\title{
Tris(8-hydroxyquinoline)iron induces apoptotic cell death via oxidative stress and by activating death receptor signaling pathway in human head and neck carcinoma cells
}

\author{
Leong-Perng Chan ${ }^{1,2}$, Ya-Ping Tseng ${ }^{3}$, Cheng Liu ${ }^{4,5}$, Hsiou-Yu Ding ${ }^{6}$, Sheng-Ming \\ Pan7, Feng-Yu Chiang ${ }^{2}$, Ling-Feng Wang', Tzung-Han Chou ${ }^{8}$, Po-Lin Kuo ${ }^{1,9}$ and \\ Chia-Hua Liang ${ }^{6}$ \\ ${ }^{1}$ Graduate Institute of Clinical Medicine, Kaohsiung Medical University, Kaohsiung, Taiwan \\ ${ }^{2}$ Department of Otolaryngology-Head and Neck Surgery, Kaohsiung Medical University Hospital, Kaohsiung Medical University, \\ Kaohsiung, Taiwan \\ ${ }^{3}$ Institute of Basic Medical Sciences, National Cheng Kung University, Tainan, Taiwan \\ ${ }^{4}$ Division of Plastic Surgery and HBOT Center, Chi Mei Medical Center, Tainan, Taiwan \\ ${ }^{5}$ Department of Electrical Engineering, Southern Taiwan University of Science and Technology, Tainan, Taiwan \\ ${ }^{6}$ Department of Cosmetic Science and Institute of Cosmetic Science, Chia Nan University of Pharmacy and Science, Tainan, \\ Taiwan \\ ${ }^{7}$ Chemical Systems Research Division-Propellant Plant, Nation Chung-Shan Institute of Science and Technology, Kaohsiung, \\ Taiwan \\ ${ }^{8}$ Department of Chemical and Materials Engineering, National Yunlin University of Science and Technology, Yunlin, Taiwan \\ ${ }^{9}$ Institute of Medical Science and Technology, National Sun Yat-Sen University, Kaohsiung, Taiwan \\ Correspondence to: Po-Lin Kuo, email: kuopolin@seed.net.tw \\ Chia-Hua Liang, email: tinna_ling@mail.cnu.edu.tw
}

Keywords: tris (8-hydroxyquinoline) iron; human head and neck carcinoma; oxidative stress; mitochondria; death receptor Received: February 24, $2017 \quad$ Accepted: December 05, $2017 \quad$ Published: January 02, 2018

Copyright: Chan et al. This is an open-access article distributed under the terms of the Creative Commons Attribution License 3.0 (CC BY 3.0), which permits unrestricted use, distribution, and reproduction in any medium, provided the original author and source are credited.

\section{ABSTRACT}

Head and neck squamous cell carcinoma (HNSCC) is associated with a high rate of mortality and novel anti-HNSCC drugs must be developed. 8-Hydroxyquinoline derivatives are associated with anti-oxidant, anti-tumor and anti-HIV-1 properties. Tris(8-hydroxyquinoline)iron (Feq3), a novel compound, was synthesized. Feq3 induced the death of HNSCC cells and caused them to exhibit the morphological features of apoptosis. Feq3 also induced apoptosis of SCC9 cells by cell cycle arrest during the G2/M phase and the induced arrest of SCC25 cells in the G0/G1 and G2/M phases, which was associated with decreased cyclin B1/cdc2 and cyclin D/cdk4 expressions. Feq3 increases reactive oxygen species (ROS) and reduces glutathione (GSH) levels, and responds to increased p53 and p21 expressions. Feq3 induced apoptosis by mitochondria-mediated Bax and cytochrome c up-expression and downexpression Bcl-2. Feq3 also up-regulated tBid, which interacts with the mitochondrial pathway and tumor necrosis factor-a (TNF-a)/TNF-Rs, FasL/Fas, and TNF-related apoptosis inducing ligand receptors (TRAIL-Rs)/TRAIL-dependent caspases apoptotic signaling pathway in HNSCC cells. However, Feq3 activates Fas but not FasL in SCC25 cells. Feq 3 arrests the growth of HNSCC cells and is involved in the mitochondria- and death receptor (DR)-mediated caspases apoptotic pathway. This study is the first to suggest that apoptosis mediates the anti-HNSCC of Feq3. Feq3 has potential as a cancer therapeutic agent against HNSCC. 


\section{INTRODUCTION}

HNSCC is the sixth most common cancer globally. Despite technical advances in surgery, chemotherapy, and radiotherapy, survival rates have remained virtually unchanged over the last 50 years $[1,2]$. Although clinical inspection by a dentist or detection of some HNSCC tumor markers is relatively easy, this carcinoma is usually ignored by patients, especially in its early stage. Therefore, HNSCC is frequently diagnosed at advanced stages, resulting in high mortality. Therefore, primary treatment modalities have increasingly shifted from surgery to molecular-targeted chemotherapy and/or radiotherapy [3], such as bleomycin, taxanes, cisplatin and 5-Fu, but they cannot improve the overall survival. Therefore, it is necessary for development of novel compounds on HNSCC.

Most current chemotherapeutic drugs induced apoptosis to arrest the growth of, and kill cancer cells [4]. Intrinsic and extrinsic pathways correspond to the two major well-studied apoptotic processes [5]. The intrinsic pathway is triggered by the stress-mediated release of cytochrome $c$ from the mitochondria, forming the apoptosome, whereas the extrinsic pathway is triggered by DRs at the cell surface [6]. The apoptosome then activates the initiator caspase, typically caspase- 9 , activating the executioner caspase-3. Members of the Bcl2 family, including Bcl-2 and Bax, can both negatively and positively regulate the mitochondrial events associated with apoptotic cell death by suppressing cytochrome $c$ expression [7]. This process results in the same apoptotic response as is observed with the extrinsic pathway. In the extrinsic pathway, the activation of caspases- 8 by the formation of death-inducing signal complex (DISC) directly induces apoptosis by the activation of caspase-3. However, in the intrinsic pathway, the cleavage of Bid by caspase- 8 is translocated to the mitochondria, releases cytochrome $c$, and consequently induces apoptosis by activation of caspase-9. The extrinsic apoptotic pathway is activated by the engagement of transmembrane DRs, which are TNF-Rs, Fas/CD95, and TRAIL-Rs by its ligands (TNF- $\alpha$, FasL, TRAIL). When a ligand binds to DRs, their cytoplasmic death domains attract adaptor molecules [typically TNF-R1-associated death domain protein (TRADD) and Fas-associated protein with death domain (FADD)] and initiate a caspase cascade. Various receptors/ligand pairs exist, such as Fas/FasL, TNF/TNFR1 and TNF-R2, TRAIL/TRAIL-R1 and TRAIL-R2; they all eventually induce the activation of caspase- 8 , which in turn activates downstream caspases, leading to apoptotic cell death $[8,9]$.

Metal complexes have a long history in the field of oncology, in particular platinum-drugs, have been investigated for the treatment of cancer for the last 40 years [10]. These complexes shows their strong cytotoxic by targeting DNA and switching the cellular redox homeostasis [11]. Iron, a critical role in physiological functions, is bound to protein that it cannot cause peroxidation or ROM (reactive oxygen metabolites) formation in the body. Iron also induces mitochondrial permeability transition [12]. However, it has been proposed as a risk factor for cancer [13]. Therefore, iron chelators might be as proper agents in cancer therapeutic. They might attack critical targets and elicit a cytotoxic on tumor by causing oxidative stress [14]. 8-Hydroxyquinoline is a well-known molecule that owing to its metal-complexation ability is commonly used for metal precipitation [15]. Previous research has established that iron that is bound to the lipophilic chelator, 8-hydroxyquinoline, is strongly toxic and may cause substantial DNA-strand breakage and lipid peroxidation in human lung A549 cells. Besides, 8-hydroxyquinoline derivatives have highly sensitive fluorescent chemosensors for metal ions, which is an important biological significance. 8-Hydroxyquinoline derivatives are important constituents in several pharmaceutically important classes of compounds and are associated with a wide range of physiological activities, including anti-tumor, anti-microbial, anti-HIV-1, antioxidant activities [16]. They also exhibit 1,1-diphenyl-2picrylhydrazyl (DPPH) free radical-scavenging activity and induce the proliferation of rat mesenchymal stem cells (rMSC) [17]. In this work, tris(8-hydroxyquinoline)iron $\left(\mathrm{Feq}_{3}\right)$, a novel compound, was synthesized. This work is the first to identify the inhibition of cell growth by $\mathrm{Feq}_{3}$ and to examine its effects on cell cycle distribution and apoptosis in HNSCC cells.

\section{RESULTS}

\section{Feq3 exhibits growth-inhibiting activity and causes apoptosis in HNSCC cells}

To synthesize $\mathrm{Feq}_{3}, 1.85 \mathrm{mM} \mathrm{FeCl} \cdot 6 \mathrm{H}_{2} \mathrm{O}$ was mixed with $0.01 \mathrm{mM}$ 8-hydroxyquinoline and the mixture was synthesized by solid phase synthesis for $40 \mathrm{~min}$ at $190^{\circ} \mathrm{C}$. From this procedure, darkslategray powder of $\mathrm{Feq}_{3}$ was obtained (yield $80 \%$ ). Figure 1A displays the chemical structure of tris(8-hydroxyquinoline)iron $\left(\mathrm{Feq}_{3}\right)$. To evaluate the growth-inhibiting activity of $\mathrm{Feq}_{3}$, the effects of $\mathrm{Feq}_{3}$ on human epidermoid carcinoma A431, differentiated HNSCC (SCC9 and SCC25), human skin basal cell carcinoma BCC, human skin melanoma A375, and human premalignant keratinocytic $\mathrm{HaCaT}$ cells were treated with increasing concentrations of $\mathrm{Feq}_{3}(0,1.6,2.0$, 4.2 and $8.2 \mu \mathrm{M}$ ) for $24 \mathrm{~h}$ and cell viability was evaluated in each case by MTT assay. As presented in Figure 1B, $\mathrm{Feq}_{3}$ inhibited the growth of cancer cells in a concentrationdependent manner, and the $\mathrm{IC}_{50}$ value of $\mathrm{Feq}_{3}$ was $2.5 \mu \mathrm{M}$ for A431, 2.3 $\mu \mathrm{M}$ for SCC9, $1.8 \mu \mathrm{M}$ for SCC25, $5.3 \mu \mathrm{M}$ for BCC, $2.9 \mu \mathrm{M}$ for A375, and $2.5 \mu \mathrm{M}$ for $\mathrm{HaCaT}$ cells, respectively. These experimental results suggest that $\mathrm{Feq}_{3}$ inhibited the growth of HNSCC (SCC9 and SCC25) cells 
more than it inhibited the growth of other cells. Treating SCC9 and SCC25 cells with $\mathrm{Feq}_{3}(2,4,8$ and $12 \mu \mathrm{M})$ for durations $(0,1,2,4,6,8,10,16$ and $24 \mathrm{~h})$ revealed that the inhibition of cell viability was depended on the period of treatment (Figure 1C). These results suggest that treatment with $\mathrm{Feq}_{3}$ induced considerable death of HNSCC cells in a time- and dose-dependent manner.

The inhibition of HNSCC cells growth by $\mathrm{Feq}_{3}$ was consistent with their morphological changes. Under microscopic examination, treating SCC9 and SCC25 cells with $\mathrm{Feq}_{3}\left(\mathrm{IC}_{50}\right.$ and $\left.\mathrm{IC}_{80}\right)$ for 4,8 and $24 \mathrm{~h}$, caused the cells initially to become spheroid, and caused membrane blebbing (Figure 1D). Following incubation with $\mathrm{Feq}_{3}\left(\mathrm{IC}_{50}\right)$ for $24 \mathrm{~h}$, Hoechst 33342 staining of cell nuclei revealed that SCC9 and SCC25 cells exhibited chromosomal condensation and the formation generated apoptotic bodies (Figure 1E). To elucidate the involvement of the apoptosis pathway that is induced by $\mathrm{Feq}_{3}$ in HNSCC cells, expressions of poly(ADPribose) polymerase (PARP) were measured by western blot analysis. Treating SCC9 and SCC25 cells with $\mathrm{Feq}_{3}$ $\left(\mathrm{IC}_{50}\right)$ for $24 \mathrm{~h}$ significantly increased the cleavage of PARP (Figure 1F). These experimental data suggest that $\mathrm{Feq}_{3}$ inhibits the growth of HNSCC cells and exhibits the morphological features of apoptosis.

\section{Feq3 induces cell cycle arrest and regulates cell cycle-related regulatory factors in HNSCC cells}

To determine the percentage of early and late apoptotic cells in $\mathrm{Feq}_{3}$-exposed cultures, conventional flow cytometry was performed using Annexin V-FITC and PI double staining. Annexin $\mathrm{V}-\mathrm{FITC}^{-} / \mathrm{PI}^{-}$cells are regarded as intact cells (I), Annexin $\mathrm{V}-\mathrm{FITC}^{-} / \mathrm{PI}^{+}$reveals necrotic cells (II), Annexin $\mathrm{V}-\mathrm{FITC}^{+} / \mathrm{PI}^{+}$reveals late apoptotic/necrotic cells (III), and Annexin ${\mathrm{V}-\mathrm{FITC}^{+}}^{+}$ $\mathrm{PI}^{-}$reveals early apoptotic cells (IV). To investigate the roles of $\mathrm{Feq}_{3}$ in apoptosis, $\mathrm{Feq}_{3}$ was used to establish an apoptosis system in HNSCC cells. As presented in Figure 2A, the treatment of SCC9 and SCC25 cells with $\mathrm{Feq}_{3}$ $\left(\mathrm{IC}_{50}\right)$ for 2, 4 and $24 \mathrm{~h}$ significantly reduced the survival rate of cells (I); increased the rates of early apoptotic (IV) and late apoptotic/necrotic cells (III), but only slightly increased the rate of necrotic cells (II), relative to control cells, indicating that $\mathrm{Feq}_{3}$ induces apoptosis rather than necrosis. The early apoptosis ratio and the late apoptosis ratio both increased in the presence of $\mathrm{Feq}_{3}$; in particular, the late apoptosis ratio increased in a time-dependent manner. When the $\mathrm{Feq}_{3}$ treated on SCC9 and SCC25 cells for $4 \mathrm{~h}$, the proportions of early apoptosis in two cell lines were 47.4 and $54.7 \%$, respectively. Compared with the control, the proportion of double-staining was 99.1 and $58.8 \%$ at $24 \mathrm{~h}$. To confirm that $\mathrm{Feq}_{3}$ can induce HNSCC cell apoptosis and that its inhibition of HNSCC cell growth is caused by perturbation of the cell cycle, the distribution of cells among cycles, and the apoptosis (sub- $\mathrm{G}_{1}$ phase) of cells were examined by flow cytometry. Treatment HNSCC cells with $\mathrm{Feq}_{3}\left(\mathrm{IC}_{50}\right.$ and $\left.\mathrm{IC}_{80}\right)$ for 4,8 and $24 \mathrm{~h}$ resulted in a time- and concentrationdependent significant increase in the proportion of cells in the sub- $G_{1}$ phase (apoptotic cells) relative to the control cells (Figure 2B). For example, treatment with $\mathrm{Feq}_{3}\left(\mathrm{IC}_{80}\right)$ for $24 \mathrm{~h}$ increased the proportions of SCC9 and SCC25 cells apoptosis (45.4 and $63.9 \%$ in sub- $\mathrm{G}_{1}$ ), respectively. Treatment with $\mathrm{Feq}_{3}\left(\mathrm{IC}_{50}\right.$ and $\left.\mathrm{IC}_{80}\right)$ for 4-8 $h$ caused an accumulation of SCC9 cells in the $\mathrm{G}_{2} / \mathrm{M}$ phase, which was associated with a significant decline in the population in the $\mathrm{G}_{0} / \mathrm{G}_{1}$ phase, suggesting that $\mathrm{Feq}_{3}$ probably arrests the cell cycle in the $\mathrm{G}_{2} / \mathrm{M}$ phase and induces the apoptosis of $\mathrm{G}_{0} / \mathrm{G}_{1}$ cells. However, the populations of SCC 25 cells in the $\mathrm{G}_{0} / \mathrm{G}_{1}$ and $\mathrm{G}_{2} / \mathrm{M}$ phases were increased upon exposure to $\mathrm{Feq}_{3}\left(\mathrm{IC}_{50}\right)$ for 4-24 h, while S population decreased. Furthermore, the in SCC25 cell populations in the $\mathrm{G}_{0} / \mathrm{G}_{1}$ and $\mathrm{G}_{2} / \mathrm{M}$ phases declined during incubation with $\mathrm{Feq}_{3}\left(\mathrm{IC}_{80}\right)$ for $24 \mathrm{~h}$ while that in the sub- $\mathrm{G}_{1}$ phase increased. These analytical results suggest that $\mathrm{Feq}_{3}$ induced the arrest of SCC9 cells in the $\mathrm{G}_{2} / \mathrm{M}$ phase of the cell cycle, and that of SCC25 cells in the $\mathrm{G}_{0} / \mathrm{G}_{1}$ and $\mathrm{G}_{2} / \mathrm{M}$ phases. Treatment with $\mathrm{Feq}_{3}$ at a high concentration for a long time may sensitive cancer cells and induces cell apoptosis.

Since $\mathrm{Feq}_{3}$ consistently altered cell cycle progression, whether it also affected the expressions of $\mathrm{G}_{0} / \mathrm{G}_{1}$ and $\mathrm{G}_{2} / \mathrm{M}$ modulators, such as cyclin $\mathrm{D} / \mathrm{cdk} 4$ and cyclin B1/cdc2, was determined. As presented in Figure $2 \mathrm{C}$, the exposure of SCC9 and SCC25 cells to Feq ${ }_{3}\left(\mathrm{IC}_{50}\right)$ for 4,8 and $16 \mathrm{~h}$ induced $\mathrm{G}_{2} / \mathrm{M}$ cell cycle arrest and considerably reduced the expression of cyclin B1 and cdc 2 in both cell species in a manner that depended on duration of exposure, as revealed by RT-PCR. Moreover, the arrest by $\mathrm{Feq}_{3}$ of SCC 25 cells in the $\mathrm{G}_{0} / \mathrm{G}_{1}$ phase was associated with a decline in the expressions of $\mathrm{G}_{0} / \mathrm{G}_{1}$ modulators, cyclin D and cdk4. These experimental results are consistent with the effects of treatment with $\mathrm{Feq}_{3}\left(\mathrm{IC}_{50}\right)$ for $24 \mathrm{~h}$, which reduced the expressions of $\mathrm{G}_{2} / \mathrm{M}$-related cyclin B1/cdc2 in both cell species, as revealed by western blotting (Figure 2D). These analytical results indicate that $\mathrm{Feq}_{3}$ induced the apoptosis of SCC9 cells by arresting the cell cycle during the $\mathrm{G}_{2} / \mathrm{M}$ phase and that of SCC25 cells by inducing their arrest in the $\mathrm{G}_{0} / \mathrm{G}_{1}$ and $\mathrm{G}_{2} / \mathrm{M}$ phases, which was associated with reduced cyclin $\mathrm{B} 1 / \mathrm{cdc} 2$ and cyclin D/cdk4 expressions.

\section{Feq3 increased ROS and depleted GSH levels in HNSCC cells}

Many chemotherapeutic drugs kill cancer cell by triggering high level ROS generation. Initiation of programmed cell death is dependent on ROS generation, it has shown to participate in the regulation of apoptosis and cell cycle arrest and also promote the sustained p53/ Bax activation [18]. 
A

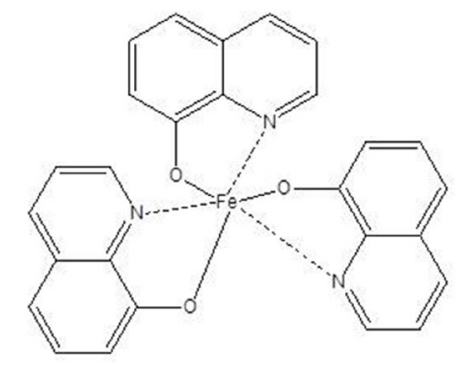

Tris(8-hydroxyquinoline)iron $\left(\mathrm{Feq}_{3}\right)$

C

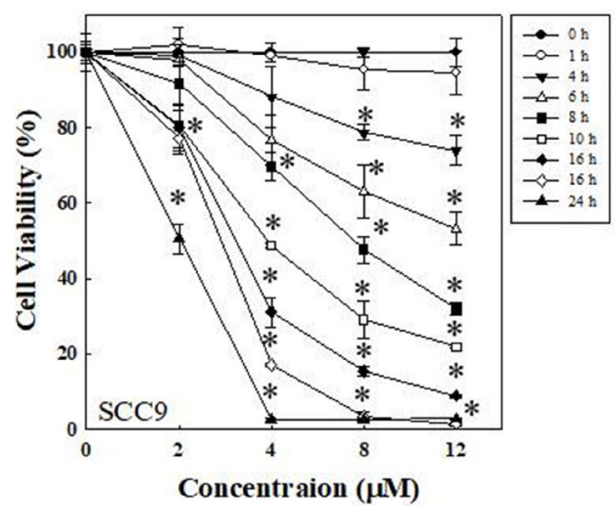

D

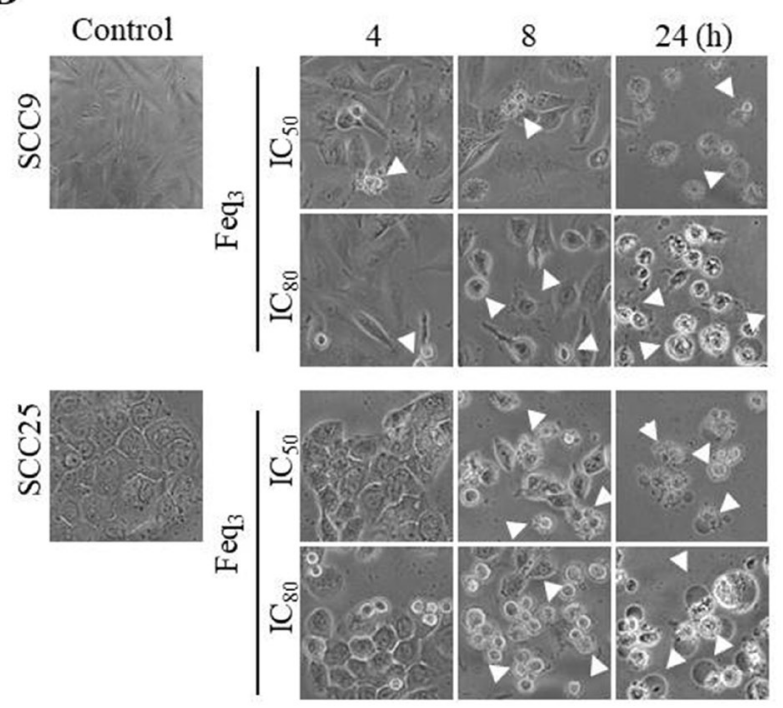

B
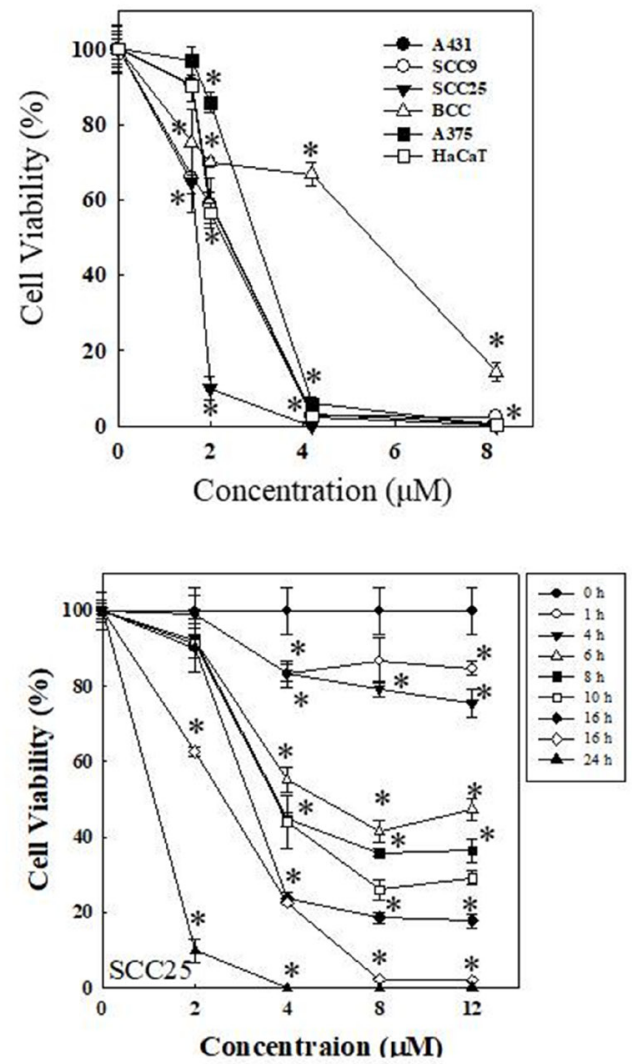

$\mathbf{E}$

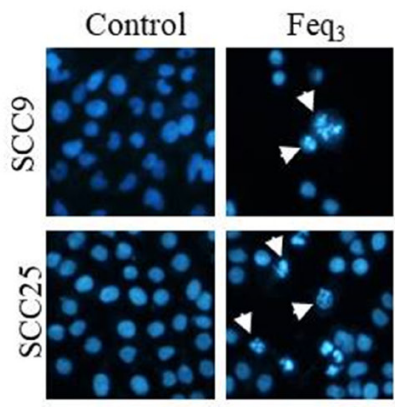

F

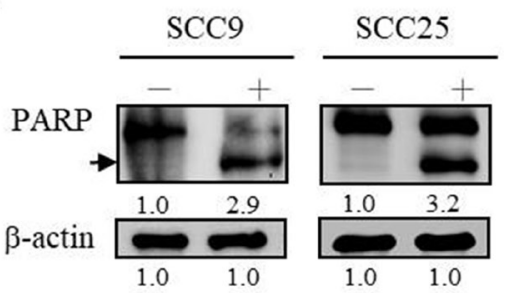

Figure 1: Dose and time-dependent activation of HNSCC cells apoptosis by Feq3. (A) Structure of tris(8-hydroxyquinoline) iron $\left(\mathrm{Feq}_{3}\right)$. (B) The effects of $\mathrm{Feq}_{3}$ in human epidermoid carcinoma A431, differentiated HNSCC (SCC9 and SCC25), human skin basal cell carcinoma BCC, human skin melanoma $\mathrm{A} 375$, and human premalignant keratinocytic $\mathrm{HaCaT}$ cells were treated with either increasing concentrations of $\mathrm{Feq}_{3}(0,1.6,2.0,4.2$ and $8.2 \mu \mathrm{M})$ or DMSO (vehicle control) for $24 \mathrm{~h}$ and the cell viability was determined by MTT assay. (C) Time and dose-related growth suppression of SCC9 and SCC25 cells is shown by constant amounts of $\mathrm{Feq}_{3}\left(\mathrm{IC}_{50}\right.$ and $\left.\mathrm{IC}_{80}\right)$ for 4, 8 and $24 \mathrm{~h}$. Cell viabilities were determined by MTT assay. Each value is the mean $\pm \mathrm{SD}$ of three individual experiments; ${ }^{*} p<0.05$ indicates a significant difference from vehicle control-treated cells. (D) $\mathrm{Feq}_{3}$ exhibit the morphological features of apoptosis in HNSCC cells. Treating SCC9 and SCC25 cells with Feq ${ }_{3}\left(\mathrm{IC}_{50}\right.$ and $\left.\mathrm{IC}_{80}\right)$ for 4, 8 and $24 \mathrm{~h}$, cell morphology was observed under an inverted phase contrast microscope (200×). (E) Cell nuclei changes in SCC9 and SCC25 cells after Feq $\left(\mathrm{IC}_{50}\right)$ treatment for $24 \mathrm{~h}$, and the nuclei were visualized by staining DNA with Hoechst 33342 (blue) and using a fluorescent microscope (200×). Arrowheads indicate cells apoptosis feature. (F) Treating SCC9 and SCC25 cells with $(+)$ or without $\mathrm{Feq}_{3}\left(\mathrm{IC}_{50}\right)$ for $24 \mathrm{~h}$, and the expressions of cleaved PARP on both cells were assessed by western blotting. $\beta$-actin was measured as the quality control. 
This study tests the possibility that $\mathrm{Feq}_{3}$ induces the apoptosis of HNSCC cells while allowing ROS accumulation, by using flow cytometry to detect changes in ROS levels. Treatment of SCC9 and SCC25 cells with $\mathrm{Feq}_{3}\left(\mathrm{IC}_{50}\right.$ and $\mathrm{IC}_{80}$ ) for 4-8 h significantly increased the amount of ROS formed, relative to that in control cells (Figure 3A). However, treatment with $\mathrm{Feq}_{3}$ for $24 \mathrm{~h}$ reduced the ROS, perhaps because a longer incubation time caused more cell death without producing ROS. Incubation of both cell species with $\mathrm{Feq}_{3}\left(\mathrm{IC}_{50}\right.$ and $\left.\mathrm{IC}_{80}\right)$ for 4, 8 and $24 \mathrm{~h}$ significantly decreased the GSH level to an extent that decreased with concentration and time, as identified by comparison with a control and analysis using flow cytometry to detect changes in GSH levels (Figure 3B). These experimental results reveal that induced oxidative stress signaling pathways in HNSCC cells and apoptosis involve increased ROS and depleted GSH levels.

In order to clarify whether $\mathrm{Feq}_{3}$ induces cell apoptosis by stimulating mitochondrial ROS generation, we used MitoSOX Red and MitoView Green to estimate the level of mitochondria ROS. ROS production upon exposure to $\mathrm{Feq}_{3}$ in SCC9 using a chemical probe of mitochondrial ROS detection (MitoSOX Red). MitoSOX Red fluorescence in the DMSO-treated control SCC9 cells was weak and diffuse. On the other hand, treatment of both SCC9 cells with $\mathrm{Feq}_{3}$ at $\mathrm{IC}_{20}$ and $\mathrm{IC}_{50}$ resulted in enrichment of MitoSOX Red fluorescence that co-localized with the mitochondria as evidenced by appearance of MitoView green-associated green fluorescence (Supplementary Figure 1). Thus, we demonstrated that mitochondria pathway is involved in apoptosis induced by $\mathrm{Feq}_{3}$. CellROX is more specific and stable than $\mathrm{DCFH}_{2} \mathrm{DA}$ and we used it to confirm whether the ROS generation in $\mathrm{Feq}_{3}$ treated SCC9. After $\mathrm{Feq}_{3}$ $\left(\mathrm{IC}_{20}\right.$ and $\left.\mathrm{IC}_{50}\right)$ treatment for $4 \mathrm{~h}$, CellROX green is strong expression than control in HNSCC cells (Supplementary Figure 2). After the results of MitoSOX and CellROX, we concluded that $\mathrm{Feq}_{3}$ induces ROS generation in HNSCC.

According to our previous data, the role of oxidative stress changes was explored during $\mathrm{Feq}_{3}$ induced apoptosis in HNSCC cells. However, the aspects of antioxidants NAC ( $N$-acetylcysteine) and BSO (buthionine sulfoximine) could provide theoretical basis for clinical treatment. $\mathrm{Feq}_{3}$ combined with NAC (a precursor of glutathione synthesis) and BSO (inhibitor of GSH synthesis) measured the intracellular ROS using CellROX. The effects of NAC or BSO on cell death were examined in $\mathrm{Feq}_{3}$-treated SCC9 cells. NAC slightly suppress cytotoxic effect induced by $\mathrm{Feq}_{3}$ and BSO increase the cytotoxic in $\mathrm{Feq}_{3}$ treated SCC9 cells (Supplementary Figure 3A and 3B). To assess whether $\mathrm{NAC}$ or BSO influences ROS level by $\mathrm{Feq}_{3}$ treating, NAC reduced ROS levels and BSO increased ROS levels in $\mathrm{Feq}_{3}$-treated $\mathrm{SCC} 9$ cells. Regarding ROS levels, NAC slightly attenuated ROS accumulation induced by Feq3 in SCC9 cells. BSO seemed to increase ROS accumulation in Feq3-treated SCC9 cells (Supplementary Figure 3C and 3D).

To define the p53 and p21-mediated cell cycle arrests that are associated with $\mathrm{Feq}_{3}$ treatment, the gene expressions of p53 and p21 in SCC9 and SCC25 cells that had been treated with $\mathrm{Feq}_{3}\left(\mathrm{IC}_{50}\right)$ for 4,8 and $16 \mathrm{~h}$ were evaluated by RT-PCR analysis. Feq ${ }_{3}$ significantly upregulated p53 and p21 expressions in a time-dependent fashion (Figure 3C). As a result of incubation with $\mathrm{Feq}_{3}$ $\left(\mathrm{IC}_{50}\right)$ for $24 \mathrm{~h}$, the protein up-expressions of $\mathrm{p} 53$ and p21 in SCC9 and SCC25 cells, as confirmed by western blotting (Figure 3D), immunofluorescence microscopy (Figure 3E) and flow cytometric analysis (Figure 3F). These analytical results suggest that $\mathrm{Feq}_{3}$ induced the apoptosis of HNSCC cells by inducing oxidative stress signaling pathways, increasing p53 and p21 levels and promoting cell cycle arrest.

\section{Feq3 modulates mitochondria-dependent proteins of Bcl-2 family and caspase apoptosis pathway in HNSCC cells}

Cytochrome $c$ is released from mitochondria to cytoplasm by ROS accumulation, which enhances caspase-3 for cell apoptosis. Bcl-2 family is crucial protagonist in mitochondrial apoptosis. The level of Bax and Bcl-2 are decisive features to determine whether cells will undergo apoptosis [19].

To determine whether $\mathrm{Feq}_{3}$ triggers mitochondriamediated apoptosis via Bcl-2 family proteins and the release of cytochrome $c$, the expressions of Bax, Bcl-2 and cytochrome $c$ were evaluated by RT-PCR, western blotting, flow cytometry and immunofluorescence analysis, respectively. Furthermore, the treatment of SCC9 and SCC25 cells with $\mathrm{Feq}_{3}\left(\mathrm{IC}_{50}\right)$ for 4, 8 and $16 \mathrm{~h}$ greatly increased Bax and cytochrome $c$ levels, and reduced Bcl-2 mRNA expression in a time-dependent manner (Figure 4A). Similar results were obtained by western blot analysis (Figure 4B), flow cytometry (Figure 4C) and immunofluorescence microscopic analysis (Figure 4D). $\mathrm{Feq}_{3}\left(\mathrm{IC}_{50}\right)$-treated cells of both species for $24 \mathrm{~h}$ up-regulated Bax and cytochrome $c$ and down-regulated Bcl-2 protein expressions. These experimental results demonstrate that $\mathrm{Feq}_{3}$ can cause apoptosis and indeed mitochondria-mediated apoptosis by modulating $\mathrm{Bcl}-2$ family member proteins in HNSCC cells.

To identify the intrinsic and extrinsic signaling pathways that underlie the $\mathrm{Feq}_{3}$-induced apoptosis of HNSCC cells, the gene activation of Bid, caspase- 9 and -8 in SCC9 and SCC25 cells following exposure to $\mathrm{Feq}_{3}$ $\left(\mathrm{IC}_{50}\right.$ ) for 4,8 and $16 \mathrm{~h}$ was measured by RT-PCR (Figure 4E). Treatment with $\mathrm{Feq}_{3} 4-16 \mathrm{~h}$ increased the expression of Bid in both cells to an extent that increased with time. The gene expressions of caspase- 9 and -8 strongly increased in both cells during treatment with $\mathrm{Feq}_{3}$ for 4-8 h. These experimental results are consistent with those of 

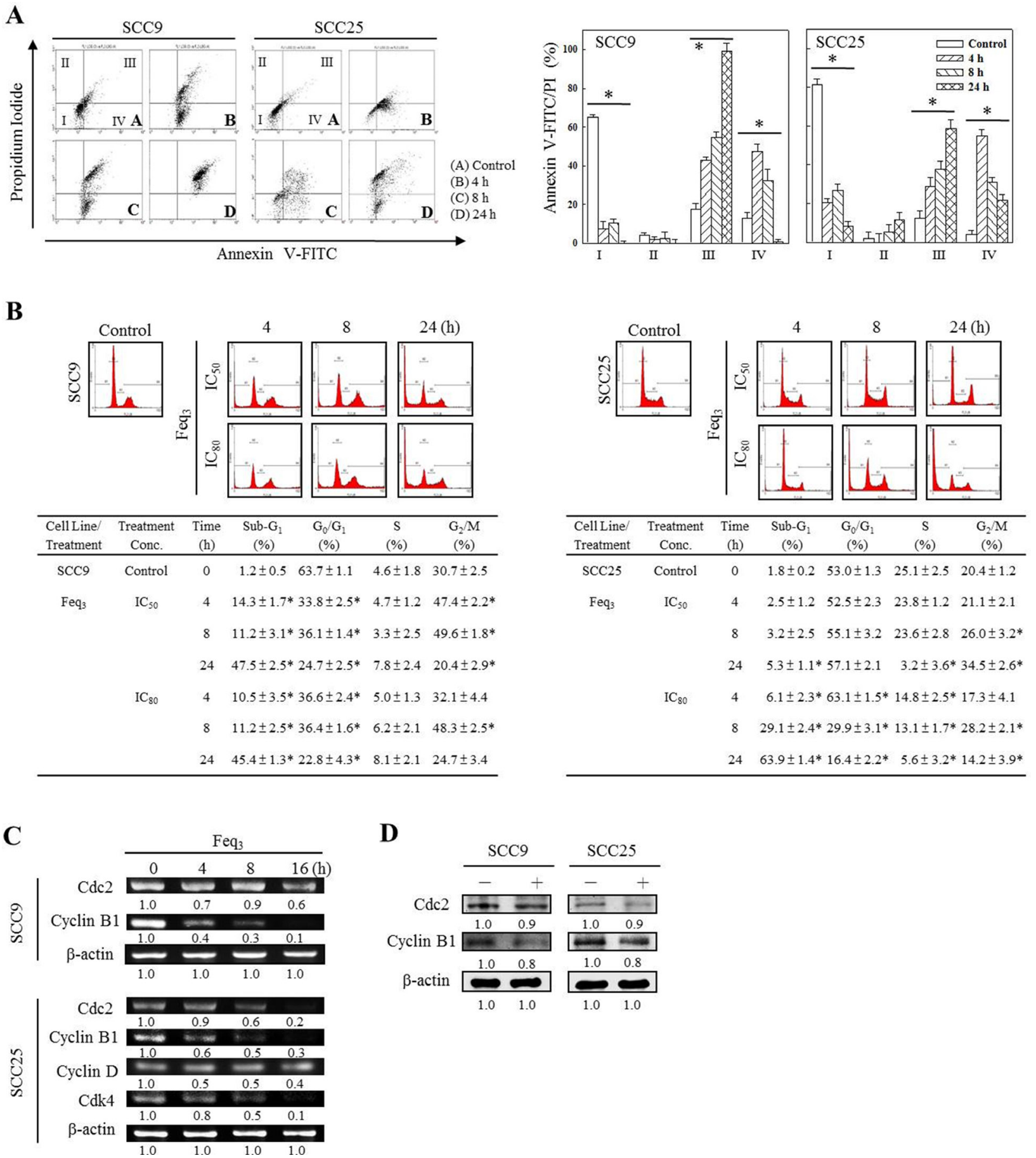

Figure 2: Feq3 induces significant apoptosis and regulates cell cycle distribution and cell cycle-related regulatory factors in HNSCC cells. (A) Apoptosis of SCC9 and SCC25 cells was assessed 4, 8 and $24 \mathrm{~h}$ after treatment with $\mathrm{Feq}_{3}\left(\mathrm{IC}_{50}\right.$ ), by Annexin V-FITC/PI double staining assay and measured by flow cytometry. The I, II, III and IV regions are signals from cells in the Annexin V-FITC $-\mathrm{PI}^{-}$cells, Annexin V-FITC $/ \mathrm{PI}^{+}$cells, Annexin V-FITC ${ }^{+} / \mathrm{PI}^{+}$cells and Annexin $\mathrm{V}-\mathrm{FITC}^{+} / \mathrm{PI}^{-}$cells, respectively. The percentage Annexin V-FITC/PI staining cells in each region was determined using WinMDI software. (B) The Feq ${ }_{3}$ induced cell cycle arrest and apoptotic cell death in $\mathrm{HNSCC}$ cells. Cells were treated with the vehicle control or $\mathrm{Feq}_{3}\left(\mathrm{IC}_{50}\right.$ and $\left.\mathrm{IC}_{80}\right)$ for 4,8 and $24 \mathrm{~h}$; percentage of apoptotic cells and cell cycle distribution were assessed by flow cytometry and using WinMDI software. The M1 region represents signals from apoptotic cells with reduced DNA content in the sub- $G_{1}$ phase; M2, M3, and M4 regions are signals from cells in the $G_{0} / G_{1}, S$, and $\mathrm{G}_{2} / \mathrm{M}$ phases, respectively. Data are mean $\pm \mathrm{SD}$ from three independent experiments; " $p<0.05$ indicated significant difference from the vehicle control-treated cells. The effect of $\mathrm{Feq}_{3}$ on cell cycle-related regulatory factors in HNSCC cells. (C) The SCC9 and SCC25 cells were treated with vehicle or the $\mathrm{Feq}_{3}\left(\mathrm{IC}_{50}\right)$ for 4,8 and $16 \mathrm{~h}$. Gene expression of cdc2 and cyclin $\mathrm{B} 1$ on SCC9 cells and cdc2, cyclin B1, cyclin D and ckd4 on SCC25 cells were determined by RT-PCR. (D) Cells were treated with $(+)$ or without $\mathrm{Feq}_{3}\left(\mathrm{IC}_{50}\right)$ for $24 \mathrm{~h}$, and the protein expressions of cdc2 and cyclin B1 were assessed by western blotting. $\beta$-actin was measured as the quality control. 
A

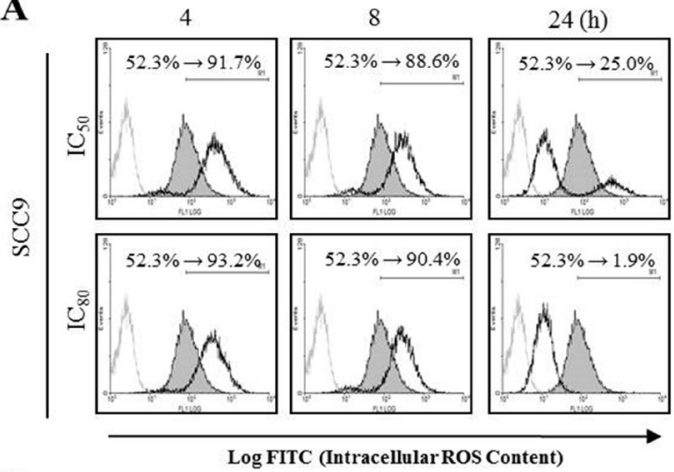

B

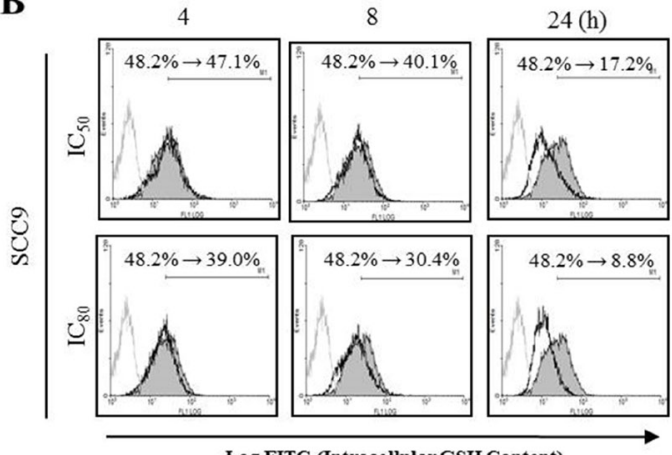

Log FITC (Intracellular GSH Content)
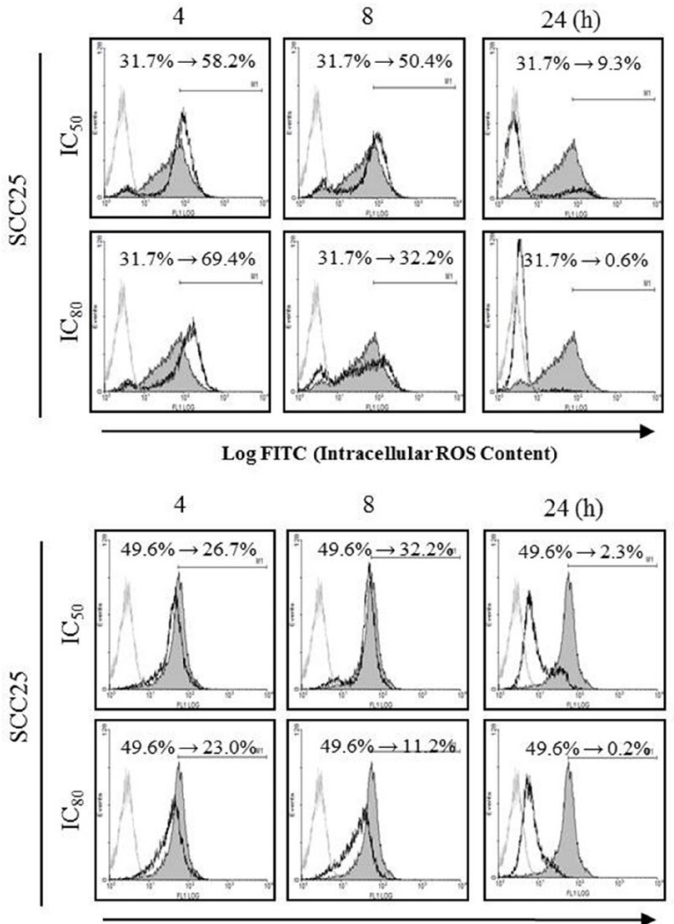

Log FITC (Intracellular GSH Content)

$$
\begin{array}{|l}
\text { - Negiative control } \\
\text { Control } \\
-\mathrm{Feq}_{3}
\end{array}
$$

C

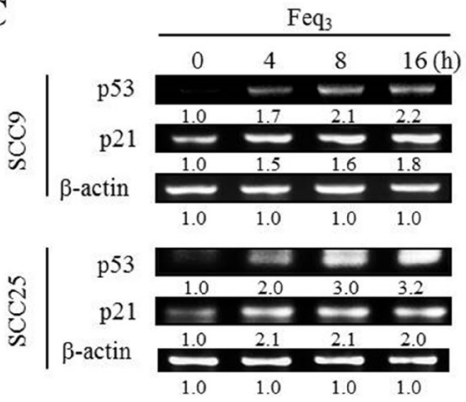

D

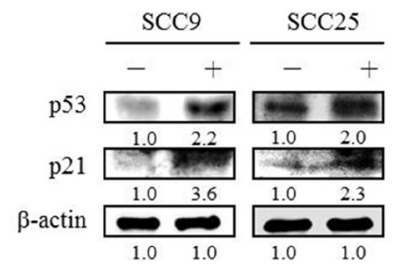

$\mathbf{E}$

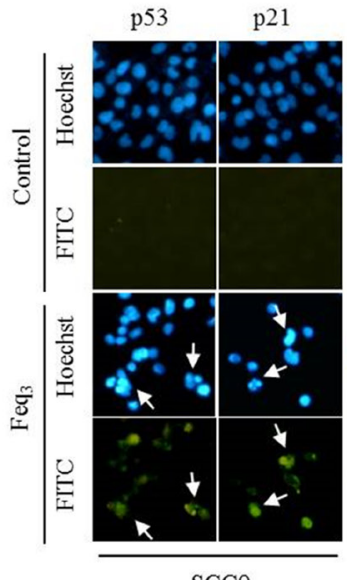

p53

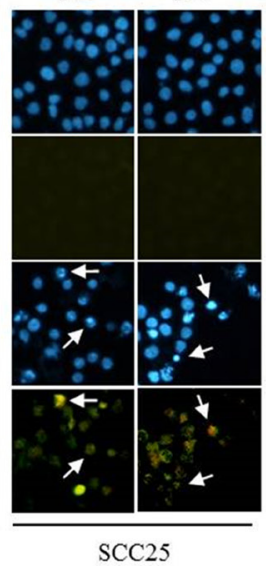

$\mathbf{F}$

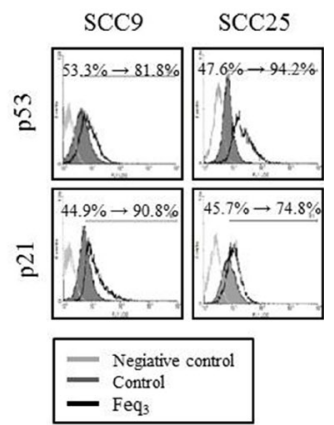

Figure 3: Feq3-induced p53 and p21 expressions and responds to diverse oxidative stress signaling pathways in HNSCC cells. SCC9 and SCC25 cells were treated with $\mathrm{Feq}_{3}\left(\mathrm{IC}_{50}\right.$ and $\left.\mathrm{IC}_{80}\right)$ for 4,8 and $24 \mathrm{~h}$, and intracellular ROS activity (A) and GSH production (B) were investigated by flow cytometry. Data concerning ROS or GSH generation reveal percentage of cells that are

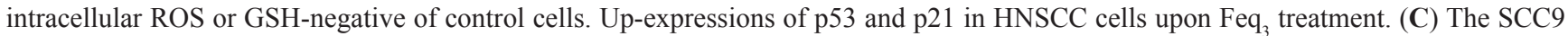
and $\mathrm{SCC} 25$ cells were treated with vehicle or the $\mathrm{Feq}_{3}\left(\mathrm{IC}_{50}\right)$ for 4,8 and $16 \mathrm{~h}$, gene expression of p53 and p21 were determined by RTPCR. Both cells were treated with $(+)$ or without $\mathrm{Feq}_{3}\left(\mathrm{IC}_{50}\right)$ for $24 \mathrm{~h}$, and the protein expressions of $\mathrm{p} 53$ and $\mathrm{p} 21$ were assessed by western blotting $(\mathbf{D})$, immunofluorescence microscopy analysis $(\mathbf{E})$ and flow cytometry $(\mathbf{F}) . \beta$-actin was measured as the quality control. Nuclei were visualized by staining DNA with Hoechst 33342 (blue) and certain protein expressions were stained with FITC (green) using a fluorescent microscope $(200 \times)$. Arrowheads indicate cells expressing a certain protein. The light-gray line implied the negative control, deep-gray line is the control, and black line is $\mathrm{Feq}_{3}$ treatment. The percentage as defined by fluorescent stained protein expression levels of cells and compared to control cells by flow cytometry. 
exposing SCC9 and SCC25 cells to $\mathrm{Feq}_{3}\left(\mathrm{IC}_{50}\right)$ for $24 \mathrm{~h}$, which significantly increased tBid, and the cleavage of caspase- 9 and -8 , as determined by immunofluorescence microscopy (Figure 4F), western blotting (Figure 4G) and flow cytometric analysis (Figure 4H). To demonstrate directly the specificity of caspase inhibitors in HNSCC cells, the effects of caspase inhibitors on the activation of caspase- 9 and -8 inhibitors in the $\mathrm{Feq}_{3}$-induced death of SCC9 cells were examined. Cells were pretreated with caspase-9 or -8 inhibitors (z-LEHD-FMK and z-IETDFMK) $1 \mathrm{~h}$ before treatment with $\mathrm{Feq}_{3}$. Pretreatment with z-LEHD-FMK and z-IETD-FMK considerably lessened the cell death that was caused by treatment with $\mathrm{Feq}_{3}$ for $24 \mathrm{~h}$ (Figure 4I), suggesting that caspase-9 and -8 were involved in $\mathrm{Feq}_{3}$-induced cell death, which influences the activation of the intrinsic mitochondrial pathway and the extrinsic DR-dependent apoptotic signaling pathway in HNSCC cells.

\section{Feq3 activities TNFRs and Fas-dependent apoptosis pathway in HNSCC cells}

Cellular stress or death signals activate DRs, causing the recruitment of the death domain, activating caspase-8 [20]. Consistent with the activation of tBid and cleaved caspase-8, DRs, such as TNF-Rs or Fas, which $\mathrm{Feq}_{3}$ through the apoptotic signaling pathway detected in HNSCC cells. Exposing SCC9 and SCC25 cells to $\mathrm{Feq}_{3}\left(\mathrm{IC}_{50}\right)$ for 4,8 and $16 \mathrm{~h}$, up-regulated the gene expressions of TNF- $\alpha$ to their receptors, TNF-R1 and TNF-R2, as determined by RT-PCR (Figure 5A). The gene expression of TNF- $\alpha$ strongly increased upon treatment of cells of both types with $\mathrm{Feq}_{3}$ for 4 to $8 \mathrm{~h}$; that of TNF-R1 increased upon treatment with $\mathrm{Feq}_{3}$ from 8 to $16 \mathrm{~h}$, and that of TNF-R2 increased upon treatment with $\mathrm{Feq}_{3}$ for $4 \mathrm{~h}$. These experimental results are consistent with the application of $\mathrm{Feq}_{3}\left(\mathrm{IC}_{50}\right)$ to SCC9 and SCC25 cells for $24 \mathrm{~h}$, which up-regulated the protein expressions of TNF- $\alpha$, TNF-R1 and TNF-R2, as revealed by immunofluorescence microscopy (Figure 5B), western blotting (Figure 5C) and flow cytometric analysis (Figure 5D). Whether treatment with $\mathrm{Feq}_{3}$ induces expression of the Fas pathway in HNSCC cells was investigated. Exposing SCC9 cells to $\mathrm{Feq}_{3}$ increased gene and protein levels of FasL/Fas, as determined by RT-PCR (Figure 5E), western blotting (Figure 5F), flow cytometry (Figure 5G) and immunofluorescence microscopy (Figure 5H), suggesting that $\mathrm{Feq}_{3}$ also induces FasL/Fas expression, which is associated with apoptosis in SCC9 cells. Nevertheless, in this work, the results of RT-PCR (Figure 5E), western blotting (Figure $5 \mathrm{~F}$ ), and flow cytometry (Figure $5 \mathrm{G}$ ) demonstrate the down-regulation of FasL level and the up-expression of Fas in SCC25 cells upon treatment with $\mathrm{Feq}_{3}$. Immunofluorescence microscopy revealed no effect on the expression of FasL in SCC25 cells (Figure 5H). The experimental results in this study indicate that TNFRs and $\mathrm{Fas}$ signals are associated with the $\mathrm{Feq}_{3}$-induced apoptosis of HNSCC cells.

\section{Feq 3 activities TRAILRs-dependent adaptor proteins and caspase- 3 apoptosis pathway in HNSCC cells}

To identify the TRAIL-Rs-mediated apoptotic pathway that is associated with the treatment of HNSCC cells by $\mathrm{Feq}_{3}$, this study evaluates the expression of TRAIL and its interaction with the expressions of TRAIL-R1 and TRAIL-2 in SCC9 and SCC25 cells that are exposed to $\mathrm{Feq}_{3}$. Cells of both types that are exposed to $\mathrm{Feq}_{3}\left(\mathrm{IC}_{50}\right)$ exhibited increased gene and protein levels of TRAIL, TRAIL-R1, and TRAIL-R2, as established by RT-RCR (Figure 6A), western blotting (Figure 6B), flow cytometry (Figure 6C), and immunofluorescence microscopy (Figure 6D). Treatment with $\mathrm{Feq}_{3}\left(\mathrm{IC}_{50}\right)$ for 4, 8 and 16 $\mathrm{h}$ increased the gene expressions of TRADD, FADD and caspase-3 in SCC9 and SCC25 cells in a time-dependent fashion, as revealed by RT-PCR (Figure 6E). Following incubation with $\mathrm{Feq}_{3}\left(\mathrm{IC}_{50}\right)$ for $24 \mathrm{~h}$, the protein expression of TRADD/FADD and the cleavage of caspase- 3 in both cells, as revealed by western blotting (Figure 6F), flow cytometry (Figure 6G) and immunofluorescence microscopy (Figure 6H). To verify that the $\mathrm{Feq}_{3}$-induced apoptosis of HNSCC cells involved caspase-3 activation, caspase-3 inhibitor z-DEVD-FMK was used. After SCC9 cells were pretreated with z-DEVD-FMK for $1 \mathrm{~h}$, they were exposed to $\mathrm{Feq}_{3}\left(\mathrm{IC}_{50}\right)$ for $24 \mathrm{~h}$. Cell viability results revealed that $\mathrm{z}$-IETD-FMK in $\mathrm{Feq}_{3}$-treated SCC9 cells inhibited the cell death that was otherwise caused by treatment with $\mathrm{Feq}_{3}$ (Figure 6I). Taken together, these results reveal that $\mathrm{Feq}_{3}$ activates the TRAILRs-dependent TRADD/FADD and caspase apoptosis pathway in HNSCC cells.

\section{DISCUSSION}

Natural and synthetic substances are becoming increasingly utilized as anti-tumor, anti-microbial, anti-oxidant and anti-pigmentation activities as well as developed pharmaceutically industry. 8-Hydroxyquinoline derivatives are associated with a broad range of physiological activities [15, 16]. Clioquinol, an 8-hydroxyquinoline derivative (5-chloro7-iodo-8-hydroxyquinoline) interacts synergistically with docosahexaenoic acid (DHA) to reduce nuclear factor$\kappa \mathrm{B}(\mathrm{NF}-\kappa \mathrm{B})$ activity and induce apoptosis; the combined effect is to reduce the levels of various molecules that promote cell survival, such as Akt, p65, and Bcl-2 [21]. Iron is a critical element in cellular metabolism and virtually all extracellular and intracellular iron is tightly bound to proteins [22]. Iron is known to catalyze the formation of reactive oxygen metabolites, which can 
A

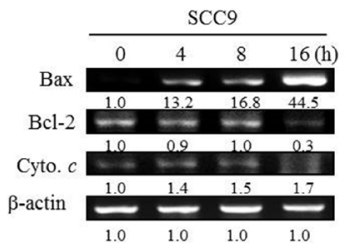

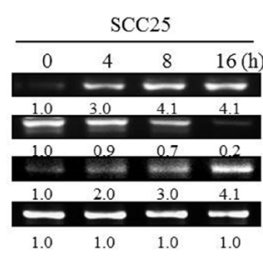

D

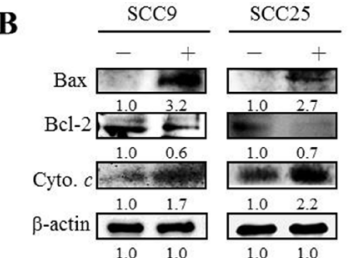

C
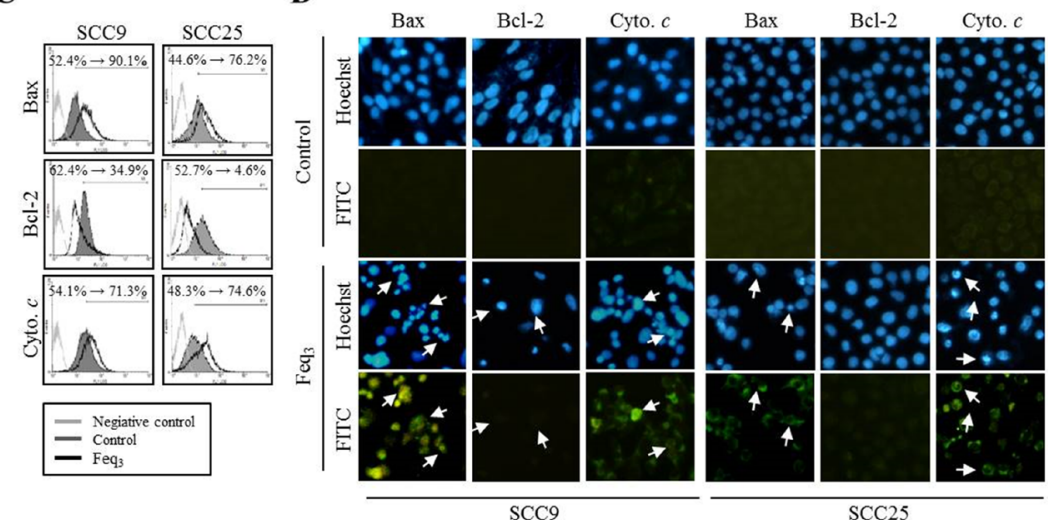

$\mathbf{E}$

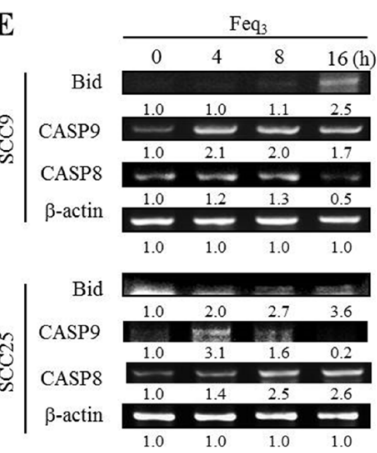

$\mathbf{F}$

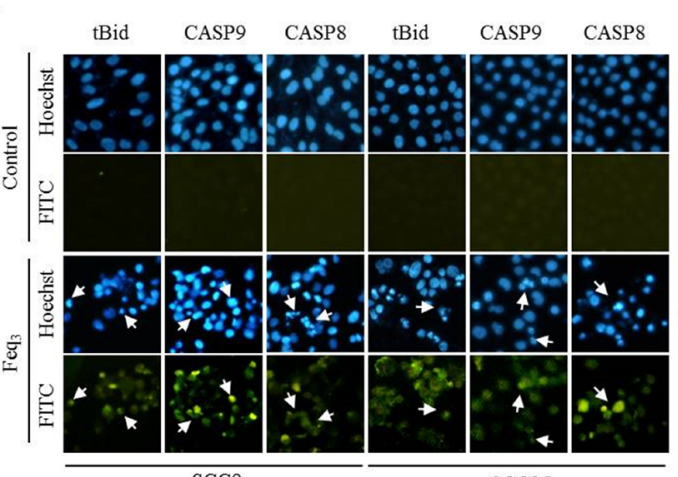

G

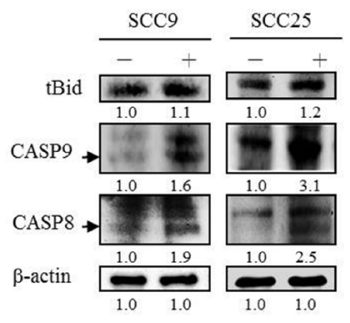

$\mathbf{H}$

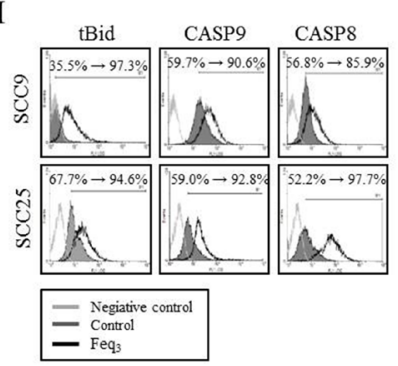

I

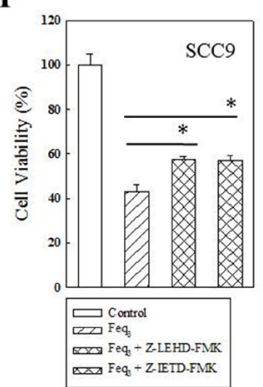

Figure 4: Regulation of mitochondria-dependent Bcl-2 family member proteins and DR-dependent caspases apoptosis pathway in HNSCC cells upon Feq3 treatment. (A) The SCC9 and SCC25 cells were treated with vehicle or the Feq 3 (IC ${ }_{50}$ ) for 4, 8 and $16 \mathrm{~h}$. Gene expression of Bax, Bcl-2 and cytochrome $c$ (cyto. $c$ ) on both cells were determined by RT-PCR. Both cells were treated with $(+)$ or without $\mathrm{Feq}_{3}\left(\mathrm{IC}_{50}\right)$ for $24 \mathrm{~h}$, and the protein expressions of Bax, Bcl-2 and cyto. $c$ were assessed by western blotting (B), flow cytometry (C) and immunofluorescence microscopy analysis (D). Changes in Bid, CASP9 (caspase-9) and CASP8 (caspase-8) gene and protein expressions in SCC9 and SCC25 cells after treatment with $(+)$ or without $(-)$ Feq $_{3}\left(\mathrm{IC}_{50}\right)$ were analyzed by RT-PCR $(\mathbf{E})$, immunofluorescence microscopy analysis $(\mathbf{F})$, western blotting $(\mathbf{G})$ and flow cytometry analysis $(\mathbf{H})$. $\beta$-actin was measured as the quality control. The light-gray line implied the negative control, deep-gray line is the control, and black line is Feq ${ }_{3}$ treatment. The percentage as defined by fluorescent stained protein expression levels of cells and compared to control cells by flow cytometry. Nuclei were visualized by staining DNA with Hoechst 33342 (blue) and certain protein expressions were stained with FITC (green) using a fluorescent microscope $(200 \times)$. Arrowheads indicate cells expressing a certain protein. (I) Pretreatment of Z-LEHD-FMK (caspase-9 inhibitor) and Z-IETD-FMK (caspase-8 inhibitor) in SCC9 cells for $1 \mathrm{~h}$ suppresses cell death by $\mathrm{Feq}_{3}\left(\mathrm{IC}_{50}\right)$. The levels of caspases were detected after treatment with the vehicle control, $\mathrm{Feq}_{3}$ and $\mathrm{Feq}_{3}$ plus the caspase inhibitors for $24 \mathrm{~h}$ by MTT assay. Data are mean \pm SD from at least three independent experiments; ${ }^{p} p<0.05$ indicates significant difference from $\mathrm{Feq}_{3}$-treated cells. 
A

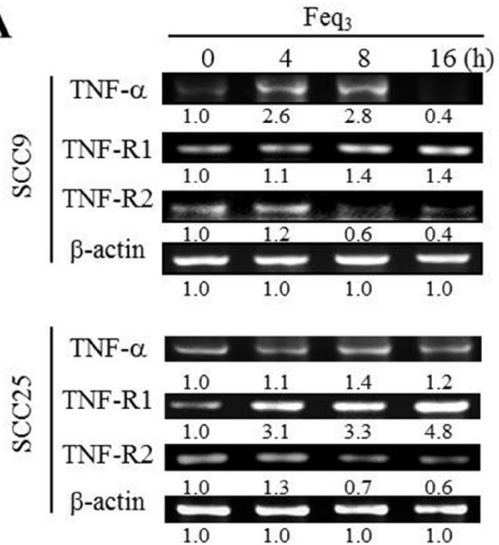

$\mathbf{C}$

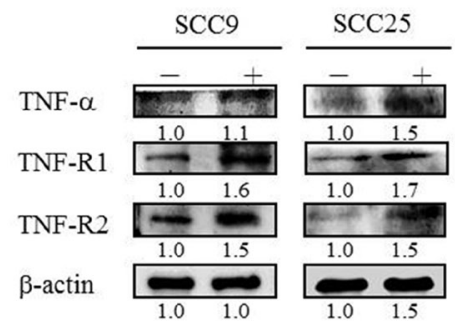

B

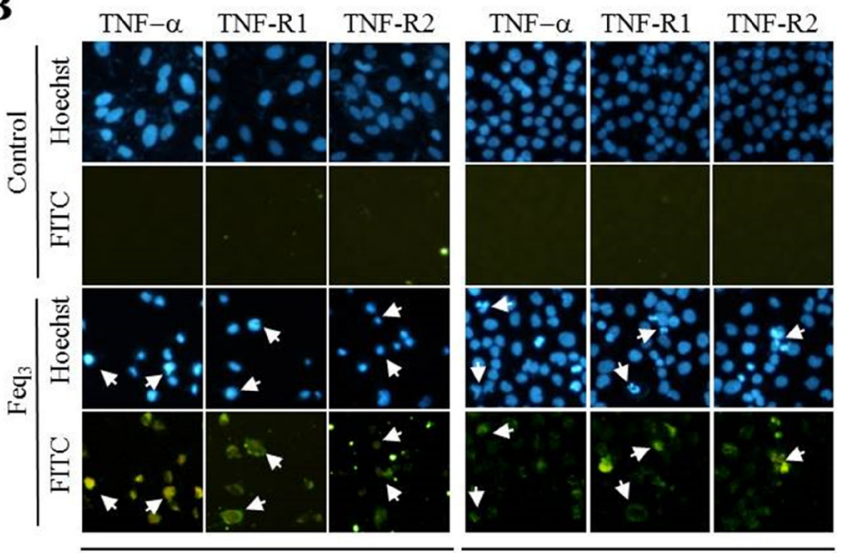

D

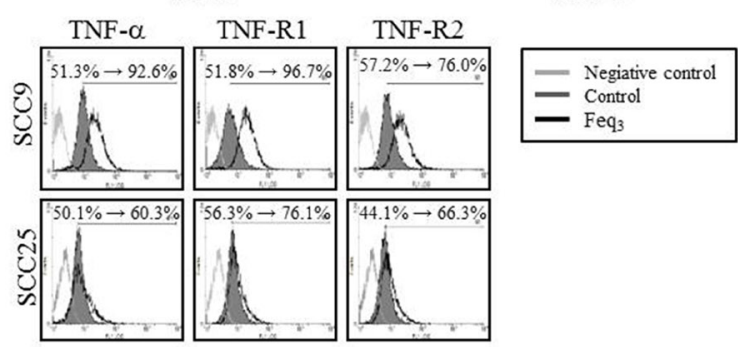

$\mathbf{E}$
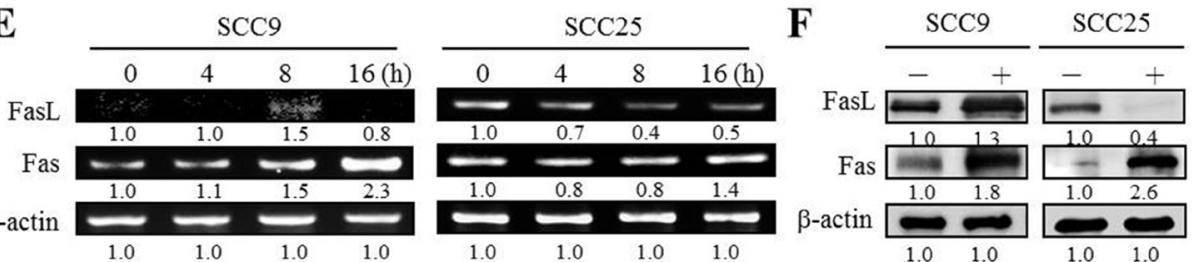

G
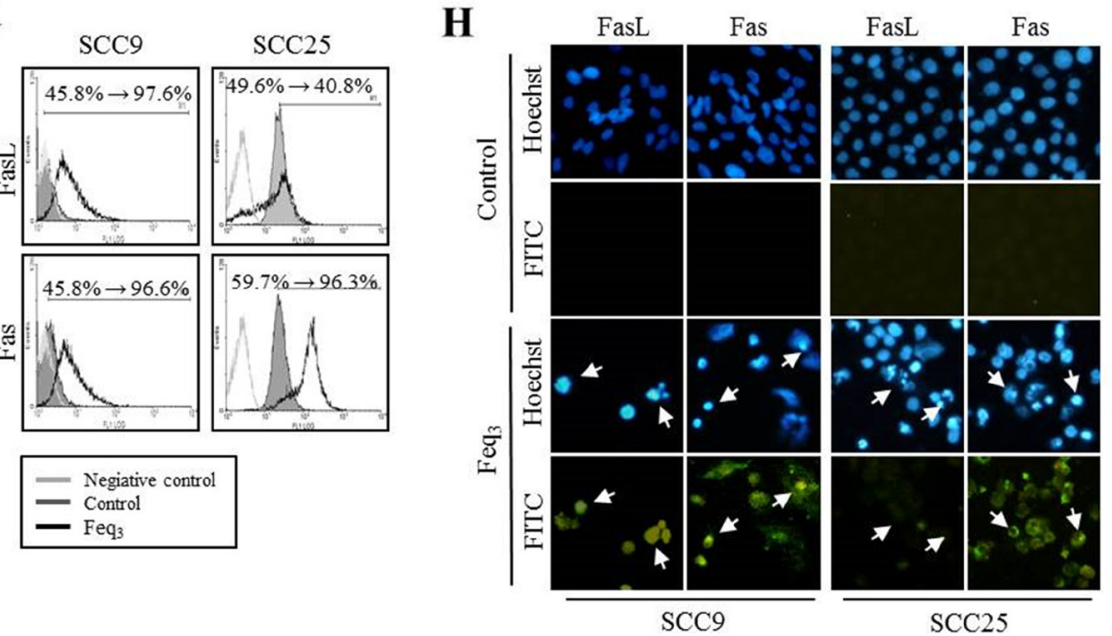

Figure 5: Expression of TNFRs and Fas-dependent apoptotic pathway in HNSCC cells after Feq3 treatment. (A) The SCC9 and SCC25 cells were treated with vehicle or the $\mathrm{Feq}_{3}\left(\mathrm{IC}_{50}\right)$ for 4,8 and $16 \mathrm{~h}$. Gene expression of TNF- $\alpha$, TNF-R1 and TNF-R2 on both cells were determined by RT-PCR. Both cells were treated with (+) or without $\mathrm{Feq}_{3}\left(\mathrm{IC}_{50}\right)$ for $24 \mathrm{~h}$, and the protein expressions of TNF- $\alpha$, TNF-R1 and TNF-R2 were assessed by immunofluorescence microscopy analysis $(\mathbf{B})$, western blotting $(\mathbf{C})$, and flow cytometry (D). Changes in FasL and Fas gene and protein expressions in both cells after treatment with $(+)$ or without $(-) \mathrm{Feq}_{3}\left(\mathrm{IC}_{50}\right)$ were analyzed by RT-PCR $(\mathbf{E})$, western blotting $(\mathbf{F})$, flow cytometry $(\mathbf{G})$, and immunofluorescence microscopy analysis $(\mathbf{H})$. $\beta$-actin was measured as the quality control. Nuclei were visualized by staining DNA with Hoechst 33342 (blue) and certain protein expressions were stained with FITC (green) using a fluorescent microscope $(200 \times)$. Arrowheads indicate cells expressing a certain protein. The light-gray line implied the negative control, deep-gray line is the control, and black line is $\mathrm{Feq}_{3}$ treatment. The percentage as defined by fluorescent stained protein expression levels of cells and compared to control cells by flow cytometry. 
damage DNA, lipids and protein, so they are important in the etiology of many diseases, including cancer. Previous reports have demonstrated that iron that is bound to 8-hydroxyquinoline, is strongly toxic in human lung A549 cells [23]. A previous study demonstrated the sensitization mechanism of tris(8-hydroxyquinoline5-carbosylic acid)iron (III) that are attached by a carboxylic acid anchor groups to the (101) surface of $\mathrm{TiO}_{2}$ anatase [24]. A new brain-permeable iron chelator, VK-28 [5-(4-(2-hydroxyethyl) piperazin-1-yl(methyl)-8 hydroxyquinoline] and its derivative M30 [5-(N-methyl-Npropargyaminomethyl)-8-hydroxyquinoline] significantly improved the behavioral performances and attenuated lactacystin-induced dopamine neuron loss, proteasomal inhibition, iron accumulation, and microglial activation of substantia nigra [25]. Tris(8-hydroxyquinoline)iron $\left(\mathrm{Feq}_{3}\right)$, a novel compound, was synthesized. This work is the first to demonstrate that $\mathrm{Feq}_{3}$ inhibits the growth of HNSCC cells and induces apoptosis of HNSCC cells via intrinsic mitochondrial and extrinsic DRs pathways.

Apoptosis is an active process of programmed cell death that proceeds with particular morphological and biochemical changes to the cells [26]. These morphological changes include externalization of phosphatidylserine on the cell surface, membrane blebbing, chromatin condensation and the formation of apoptotic bodies [19]. Previous studies have demonstrated that PARP, which is catalytically activated by DNA strand breaks, has been implicated in apoptosis [27]. Feq ${ }_{3}$ caused the cells membrane blebbing, chromosomal condensation and formed apoptotic bodies as well as increased the cleavage of PARP, suggesting that $\mathrm{Feq}_{3}$ inhibits the growth of HNSCC cells and exhibits the morphological features of apoptosis.

Annexin V-FITC is a cellular protein that is used to detect apoptotic cells, and PI dye is an intercalating agent that is commonly used to identify dead cells [28]. The characteristic feature of tumor cells is their uncontrolled growth as a result of alterations in many molecules and regulatory pathways that are involved in cell cycle control. Mitogenic signals induce expression of cyclin D and its binding to cyclin-dependent kinase 4 (cdk4) in the $\mathrm{G}_{0} /$ $\mathrm{G}_{1}$ phase of the cell cycle. The activity of the cyclin B1/ cdc2 (cdk1) complex is critical in regulating the $\mathrm{G}_{2} / \mathrm{M}$ phase [29]. Treatment with $\mathrm{Feq}_{3}$ with HNSCC cell, early and late apoptosis ratios increased significantly. The cell population in the $\mathrm{G}_{0} / \mathrm{G}_{1}$ and $\mathrm{G}_{2} / \mathrm{M}$ reduced concurrently with the sub- $G_{1}$ population in HNSCC cells, which increased after incubation with $\mathrm{Feq}_{3}$. Feq $\mathrm{F}_{3}$ induced the apoptosis of SCC9 cells by arresting the cell cycle during the $\mathrm{G}_{2} / \mathrm{M}$ phase. Otherwise, it also induced arrest in the $\mathrm{G}_{0} /$ $\mathrm{G}_{1}$ and $\mathrm{G}_{2} / \mathrm{M}$ phases in $\mathrm{SCC} 25$, which was associated with reduced cyclin $\mathrm{B} 1 / \mathrm{cdc} 2$ and cyclin $\mathrm{D} / \mathrm{cdk} 4$ expressions.

Recent research indicates that the cellular oxidation reduction (redox) state affects the cytotoxicity of several chemotherapeutic agents [30]. ROS in cells are the major endogenous oxidants. ROS have been implicated as pivotal in $\mathrm{Feq}_{3}$-induced apoptosis. A previous investigation demonstrated that adding ROS producers, and depleting reducing substances, such as GSH, favors the drug's cytotoxicity [31]. Several chemotherapeutic drugs can induce apoptosis by exhausting the intracellular thio buffer system by GSH depletion or redistribution [32]. $\mathrm{Feq}_{3}$ induces HNSCC cells death by promoting ROS formation and GSH depletion. These analytical results suggest that ROS and GSH may even determine cellular susceptibility to $\mathrm{Feq}_{3}$, because cells that contain more ROS and less GSH may be more sensitive to the drug.

The tumor-suppressor $\mathrm{p} 53$ responds to a wide range of cellular stresses by arresting cell cycle progression through the expression of p53 target genes such as p21. The expression of $\mathrm{p} 53$ downstream target $\mathrm{p} 21$ has been identified as responsible for $\mathrm{G}_{2} / \mathrm{M}$ arrest [33]. $\mathrm{Feq}_{3}$ induces HNSCC cells death by promoting ROS formation and GSH depletion. Investigations have established that p53 interacts with the pro- and anti-apoptotic members of the Bcl-2 family. p53 binds directly to trigger the oligomerization of pro-apoptotic Bax, and inhibits antiapoptotic Bcl-2; both processes, are required to disrupt mitochondria and the release of cytochrome $c$ from mitochondria into cytosol, causing activation of the intrinsic pathway [34]. Incubation with $\mathrm{Feq}_{3}$ in $\mathrm{HNSCC}$ cells, Bax and cytochrome $c$ are activated and the expression correlated with Bcl-2 reduction, suggesting that $\mathrm{Feq}_{3}$ can cause apoptosis via mitochondria-mediated Bcl-2 family member proteins in HNSCC cells.

Mitochondria have a critical role in signal transduction in apoptosis; however, activation of the mitochondrial pathway is not the only mechanism by which $\mathrm{Feq}_{3}$ may induce the apoptosis of HNSCC cells. Studies have demonstrated that the activation of p53 induces the up-regulation of Bax, resulting in the activation of the Bcl-2 family member tBid, that it interacts with the activation of the intrinsic mitochondrial pathway and the extrinsic DR-dependent apoptotic signaling pathway, and thereby activating caspase-9 and -8 [35]. Treatment with $\mathrm{Feq}_{3}$ elevated the expression of tBid in HNSCC cells. In agreement with activation of tBid, the DRs, such as TNFRs, Fas or TRAIL-Rs that proceeded through the apoptotic pathway were identified. The proapoptotic TRAIL-Rs, DR4 (TRAIL-R1) and DR5 (TRAIL-R2), are members of the death domain-containing DR family. Unlike other DRs, such as TNF-R and Fas, TRAIL-R1 and TRAIL-R2, when stimulated by the cognate ligand, TRAIL, can be utilized anticancer therapy because they induce apoptosis in cancer cells with little or no toxicity to normal cells; therefore, TRAIL-receptor agonists are currently undergoing clinical trials for the treatment of cancer [36]. Cellular stress or death signals activate DRs, leading to the recruitment of TRADD and FADD, and death domain binding, which activates caspase- 8 and contributes to the activation of caspase-3 [22]. HNSCC cells treating 
A

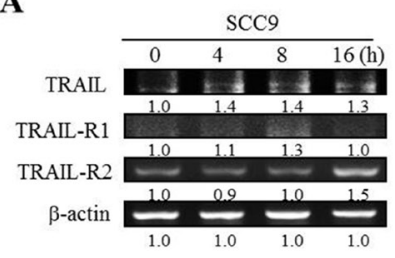

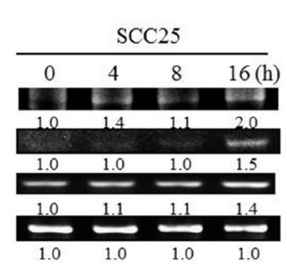

B

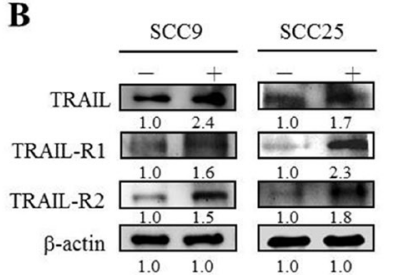

C

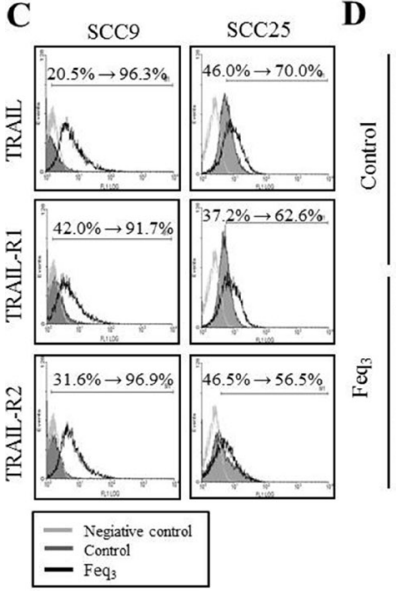

D
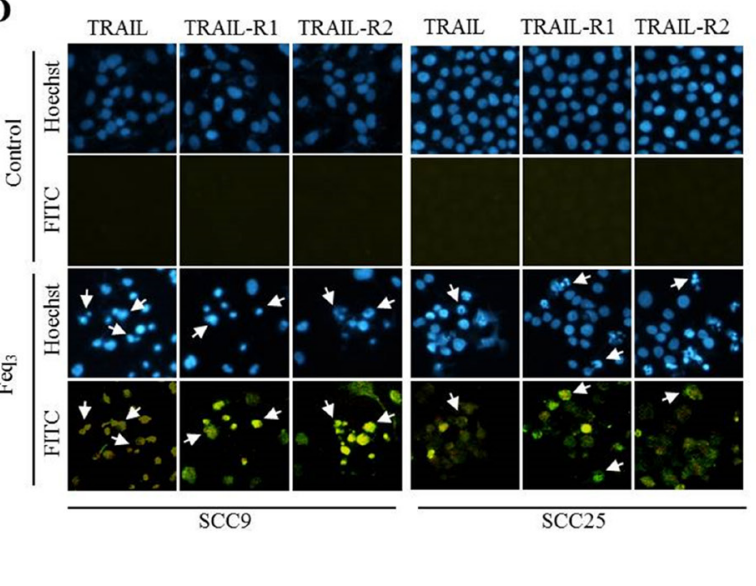

$\mathbf{E}$
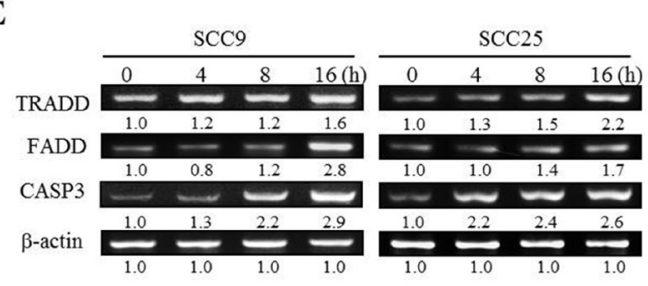

$\mathbf{F}$

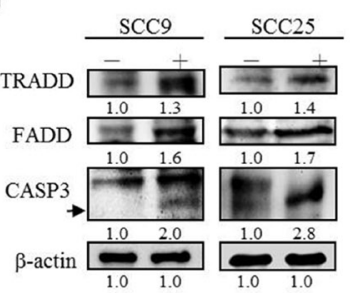

$\mathbf{G}$

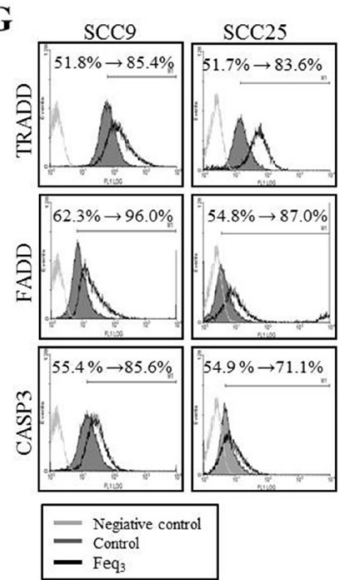

H
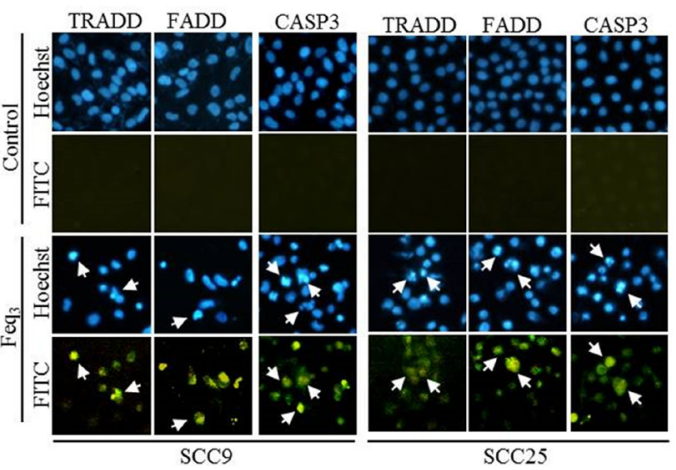

I

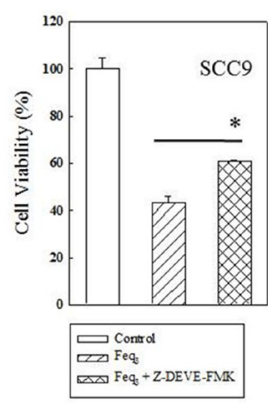

Figure 6: Expression of TRAILRs-dependent adaptor proteins and caspase-3 apoptosis pathway in HNSCC cells after Feq3 treatment. (A) The SCC9 and SCC25 cells were treated with vehicle or the $\mathrm{Feq}_{3}\left(\mathrm{IC}_{50}\right)$ for 4, 8 and $16 \mathrm{~h}$. Gene expression of TRAIL, TRAIL-R1 and TRAIL-R2 on both cells were determined by RT-PCR. Both cells were treated with $(+)$ or without Feq $_{3}\left(\mathrm{IC}_{50}\right)$ for $24 \mathrm{~h}$, and the protein expressions of TRAIL, TRAIL-R1 and TRAIL-R2 were assessed by western blotting (B), flow cytometry (C), and immunofluorescence microscopy analysis (D). Changes in TRADD, FADD and CASP3 (caspase-3) gene and protein expressions in both cells after treatment with $(+)$ or without $(-) \mathrm{Feq}_{3}\left(\mathrm{IC}_{50}\right)$ were analyzed by RT-PCR $(\mathbf{E})$, western blotting $(\mathbf{F})$, flow cytometry $(\mathbf{G})$, and immunofluorescence microscopy analysis $(\mathbf{H})$. $\beta$-actin was measured as the quality control. The light-gray line implied the negative control, deep-gray line is the control, and black line is $\mathrm{Feq}_{3}$ treatment. The percentage as defined by fluorescent stained protein expression levels of cells and compared to control cells by flow cytometry. Nuclei were visualized by staining DNA with Hoechst 33342 (blue) and certain protein expressions were stained with FITC (green) using a fluorescent microscope $(200 \times)$. Arrowheads indicate cells expressing a certain protein. (I) Pretreatment of Z-DEVE-FMK (caspase-3 inhibitor) in SCC9 cells for $1 \mathrm{~h}$ suppresses cell death by Feq (IC $_{50}$ ). The levels of caspase-3 were detected after treatment with the vehicle control, $\mathrm{Feq}_{3}$ and $\mathrm{Feq}_{3}$ plus the caspase-3 inhibitor for $24 \mathrm{~h}$ by MTT assay. Data are mean $\pm \mathrm{SD}$ from at least three independent experiments; ${ }^{*} p<0.05$ indicates significant difference from Feq ${ }_{3}$-treated cells. 
with $\mathrm{Feq}_{3}, \mathrm{Feq}_{3}$ up-regulated DRs-mediated pathway by activating death ligands TNF- $\alpha$, FasL and TRAIL to their receptors TNFRs, Fas and TRAIL-Rs, which can trigger apoptosis by recruiting TRADD and FADD, and activating of caspase- 8 and caspase-3. Exposing SCC9 cells to $\mathrm{Feq}_{3}$ increased FasL/Fas, suggesting that $\mathrm{Feq}_{3}$ induces FasL/Fas expression. Nevertheless, $\mathrm{Feq}_{3}$ induces the Fas but reduces FasL level in SCC25 cell.

In 2014, Barilli et al. indicated that iron and copper 8-hydroxyquinoline cause paraptotic death of HeLa cancer cell. They investigated 8-hydroxyquinoline derivatives by introducing different moieties near the nitrogen atom of the quinolinic system, thus the structures are different with metal tris(8-quinolinolato) chelates. Nevertheless, the study showed that $\mathrm{Cu} / \mathrm{L} 14$ and Fe/L14 (8-hydroxyquinoline derivatives) induce intracellular levels of ROS in HeLa cells and copper and iron induce a considerable oxidative stress, possibly causing the oxidation of the catalytic cysteines of caspases [37]. Tris(8-quinolinolato)gallium(III) (KP-46) is caspaseindependent cell death induction in lung (A427) and colon cancer (HCT116). KP46-induced cell death lacked classic apoptotic features and was insensitive toward a pan-caspase inhibitor at 4-6 h [38]. However, in 2016,
Wilfinger et al. demonstrated that KP-46 caused caspase-3 cleaved after $48 \mathrm{~h}$ in p53 wild-type (HCT116 ${ }^{\mathrm{WT}}$ ). Besides, they thought that the cytotoxic mechanism of KP46 is an early autophagic cell death type which is reinforced by a late caspase-dependent cell death pathway [39]. Altogether, $\mathrm{Feq}_{3}$ could mediate cell death through caspase cleavage, but it might be observed for longer exposures.

Evidence indicates that Fas can be activated in a FasL-independent manner, suggesting that Fas can also receive instructions from within the cell [40]. Cells can determine their own demise by activating Fas without any external influence by its ligand [26]. A number of reports have showed that preventing Fas/FasL interactions does not prevent apoptosis that is induced by doxorubicin with additional cytotoxic drugs [41]. Numerous antitumor drugs, including edelfosine, cisplatin, etoposide, and vinblastine, act by the FasL-independent activation of Fas [42]. Experimental data indicate that $\mathrm{Feq}_{3}$ activates Fas but reduces FasL expression in SCC25 cells. Taken together, these results reveal that $\mathrm{Feq}_{3}$ activates the DRsdependent TRADD/FADD and caspase apoptosis pathway in HNSCC cells.

The data herein suggest that the treatment of HNSCC cells with $\mathrm{Feq}_{3}$ inhibited the growth of those

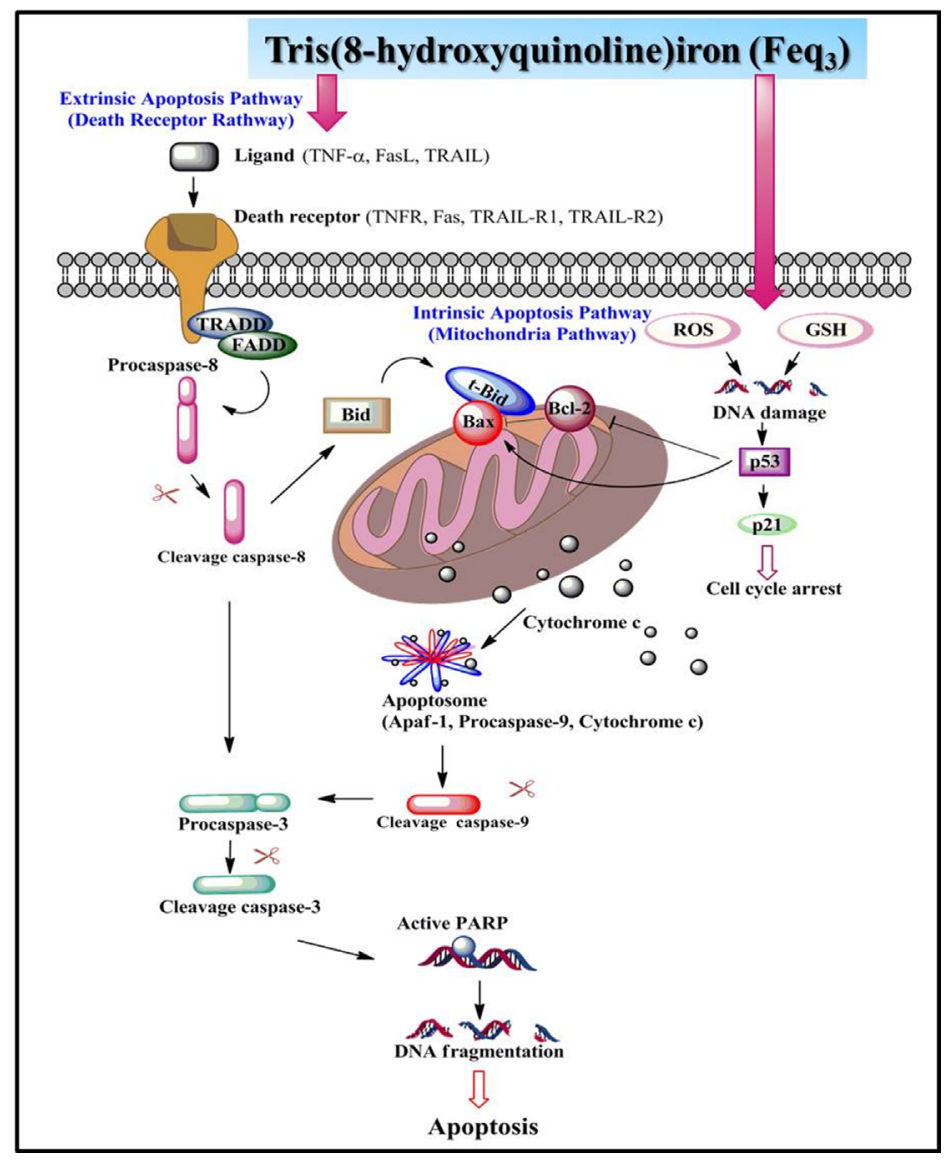

Figure 7: The proposed signaling pathways of tris(8-hydroxyquinoline)iron (Feq3) induces the apoptotic cell death via cell cycle arrest, oxidative stress, intrinsic mitochondrial pathway and extrinsic death receptor signaling pathway activation in HNSCC cells. 
cells and induced their apoptosis. (a) $\mathrm{Feq}_{3}$ induced the apoptosis of SCC9 cells arresting the cell cycle in the $\mathrm{G}_{2} / \mathrm{M}$ phase and induced the arrest of the cell cycle of SCC25 cells in the $\mathrm{G}_{0} / \mathrm{G}_{1}$ and $\mathrm{G}_{2} / \mathrm{M}$ phases; this arrest was associated with reduced cyclin $\mathrm{B} 1 / \mathrm{cdc} 2$ and cyclin $\mathrm{D} / \mathrm{cdk} 4$ expressions. (b) $\mathrm{Feq}_{3}$ induced oxidative stress signaling pathways in SCC9 and SCC25 cells, apoptosis that involving increased ROS and depleted GSH levels, and the activation of p53 and p21. (c) $\mathrm{Feq}_{3}$ induced mitochondria-mediated apoptosis by promoting the release of cytochrome $c$, increasing the expression of Bax, and reducing that of Bcl-2. (d) $\mathrm{Feq}_{3}$ activated tBid, which interacts with the activation of the intrinsic mitochondrial pathway and the extrinsic DR-dependent apoptotic signaling pathway, which in turn activates caspase-9 and -8. (e) TNFRs/TNF- $\alpha$ and TRAILRs/ TRAIL recruit TRADD/FADD signals and are thereby associated with the $\mathrm{Feq}_{3}$-induced apoptosis of HNSCC cells; however, Fas-mediated apoptosis does not involve FasL by $\mathrm{Feq}_{3}$ in $\mathrm{SCC} 25$ cell death. (f) $\mathrm{Feq}_{3}$ activated caspase-3, promoted PARP cleavage and induced the apoptosis of HNSCC cells. The analytical results herein reveal that $\mathrm{Feq}_{3}$ induced the apoptosis of HNSCC cells by activating both mitochondria- and death receptordependent caspase signaling pathways. However, other pathways may also have a role, which requires in-depth investigation. This study of the molecular mechanisms of the anti-tumor effects of tris(8-hydroxyquinoline) iron $\left(\mathrm{Feq}_{3}\right)$ in HNSCC cells may stimulate new ideas concerning the development of effective anticancer therapies.

\section{MATERIALS AND METHODS}

\section{Reagents and cell lines}

Tris(8-hydroxyquinoline)iron $\left(\mathrm{Feq}_{3}\right)$ was synthesis by Sheng-Ming Pan, Chemical Systems Research Division-Propellant Plant, Nation Chung-Shan Institute of Science \& Technology, Kaohsiung, Taiwan. Feq 3 was dissolved at a concentration of $100 \mathrm{mM}$ in dimethyl sulfoxide (DMSO) stock solution. The stock solution was diluted to the desired final concentrations with growth medium just before use. The final DMSO concentration did not exceed $0.1 \%$. The preferential caspase-9 inhibitor z-LEHD-FMK, caspase- 8 inhibitor z-IETD-FMK, and caspase-3-like inhibitor z-DEVDFMK, added to a final concentration of $200 \mu \mathrm{M}$, were used $1 \mathrm{~h}$ prior to $\mathrm{Feq}_{3}$ exposure (R\&D Systems, Inc., Palo Alto, CA, USA).

Human epidermoid carcinoma A431, human head and neck squamous cell carcinoma SCC9 (moderate differentiation) and SCC25 (well differentiation), human skin basal cell carcinoma BCC, and human skin melanoma A375 were purchased from the American Type Culture Collection (Rockville, Maryland).
Human premalignant keratinocytic $\mathrm{HaCaT}$ cells were kindly provided by Prof. Hamm-Ming Sheu (National Cheng Kung University Medical College, Tainan, Taiwan). A431, A375 and HaCaT cells were cultured in Dulbecco's modified Eagle's medium (DMEM), SCC9 and SCC25 cells in DMEM/F12 medium supplemented with $0.4 \mu \mathrm{g} / \mathrm{ml}$ hydrocortisone, and $\mathrm{BCC}$ cells were cultured in RPMI-1640 medium (GIBCO, Grand Island, NY). Cells were cultured in medium supplemented with 10\% fetal bovine serum (FBS) (Hazelton Product, Denver, PA, USA) and 1\% penicillin-streptomycin at $37^{\circ} \mathrm{C}$ in $5 \% \mathrm{CO}_{2}$.

\section{Cell viability and morphological assays}

Cells were seeded at a density of $1 \times 10^{5}$ cells $/ \mathrm{ml}$ in 96-well plates (Corning, Elmira, NY) for $24 \mathrm{~h}$ and then treated with serial concentrations of $\mathrm{Feq}_{3}$ in $100 \mu \mathrm{l}$ of medium for $24 \mathrm{~h}$. For time-course of $\mathrm{Feq}_{3}$-induced cell death analysis, cells were treated with 2, 4, 8 and 12 $\mu \mathrm{M} \mathrm{of} \mathrm{Feq}_{3}$ for 1, 2, 4, 6, 8, 10, 16 and $24 \mathrm{~h}$. Control cultures received the same amounts of DMSO as did the treated cultures. Subsequently, the medium was replaced with new medium. Cell viability was analyzed using a colorimetric MTT (3-(4, 5-dimethylthiazol-2yl)-2,5-diphenyltetrazolium bromide)-based cell growth determination kit (Promega, Madison, WI) and absorbance values were presented as a percentage relative to vehicle control (DMSO) cells. After treatment $\mathrm{Feq}_{3}$ for $24 \mathrm{~h}$, the $\mathrm{IC}_{20}, \mathrm{IC}_{50}$ and $\mathrm{IC}_{80}$ values were calculated from the drug concentration that induced 20,50 and $80 \%$ of the cell survival rate. For morphological analysis, after incubation $\mathrm{IC}_{50}$ and $\mathrm{IC}_{80}$ concentrations of $\mathrm{Feq}_{3}$ for 4,8 and $24 \mathrm{~h}$, the cells in each well were washed once with $1 \times$ PBS and performed using phase contrast inverted light microscope (Nikon, TE2000-U, Japan).

\section{Immunofluorescence and western blot assays}

Cells $\left(1 \times 10^{5}\right.$ cells $\left./ \mathrm{ml}\right)$ were treated with $\mathrm{IC}_{50}$ concentrations of $\mathrm{Feq}_{3}$ for $24 \mathrm{~h}$, and immunofluorescence and western blot assays were performed. For immunofluorescence analysis, cells were incubated with anti-p53, p21, Bax, Bcl-2, cyto. c, cleaved CASP9, cleaved CASP8, TNF-R1, Fas, TRAIL-R1, TRAIL-R2, TRADD, FADD and cleaved CASP3 $(1 \mu \mathrm{g} / \mathrm{ml})$, anti-tBid and TNF-R2 (10 $\mu \mathrm{g} / \mathrm{ml})$, and TNF- $\alpha$, FasL and TRAIL (50 $\mu \mathrm{g} / \mathrm{ml}$ ) in PBS containing $0.5 \%$ BSA and $0.1 \%$ sodium azide for $1 \mathrm{~h}$ at $4^{\circ} \mathrm{C}$. Cells were washed twice with ice-cold $1 \times$ PBS and incubated with FITC-conjugated human IgG (1:1000) (Santa Cruz, CA) as the secondary antibodies at $4^{\circ} \mathrm{C}$ for $1 \mathrm{~h}$. For fluorescence immunocytochemistry analysis, cells were fixed in $4 \%$ paraformaldehyde and stained with $0.1 \mu \mathrm{g} / \mathrm{ml}$ of Hoechst 33342 (Promega, USA) to study the nuclear morphology. The specific protein expressions and cell nuclei were photographed by 
fluorescent microscope (Nikon, TE2000-U, Japan). For flow cytometry analysis, the negative controls, the primary antibodies were replaced with $1 \times$ PBS under the same conditions. Two additional washing steps with ice-cold $1 \times$ PBS were performed before the cells were analyzed by FACScan flow cytometer (Becton-Dickinson) and a minimum of 10,000 events were acquired for analysis by WinMDI software. For western blot analysis, the whole cell lysates were prepared and analyzed with antibodies against p53, p21, Cdc2, Cyclin B1, Bax, Bcl-2, TNF- $\alpha$, FasL, Fas, TRAIL, TRADD, FADD and $\beta$-actin (Santa Cruz, CA), TNF-R1, TNF-R2, TRAIL-R1 and TRAIL-R2 (R\&D), cyto. $c$ and tBid (BD Transduction Laboratories), and PARP, cleaved CASP9, cleaved CASP8 and cleaved CASP3 (Cell Signaling Technology), respectively, as described elsewhere $[5,6]$. Proteins were visualized using enhanced chemiluminescence (ECL) reagent and their relative expressions were determined by densitometry using the Image $\mathrm{J}$ software program, and normalized relative to $\beta$-actin.

\section{Annexin-V and propiduim iodide (PI) staining assay}

Annexin V-PI apoptosis detection kit was purchased from BD Biosciences (BD Biosciences, San Jose, CA). Samples were prepared according to the manufacturer's recommended protocol. Cells $\left(1 \times 10^{5}\right.$ cells $\left./ \mathrm{ml}\right)$ were treated with $\mathrm{IC}_{50}$ concentrations of $\mathrm{Feq}_{3}$ for 4,8 and 24 h. Cells were incubated with Annexin V-FITC and PI. Stained cells were analyzed using a FACScan flow cytometer (Beckman Coulter, $\mathrm{XL} \cdot \mathrm{MCL}^{\mathrm{TM}}$, USA) and determined using WinMDI software.

\section{Cell-cycle distribution and apoptotic cells assay}

Cells were starved in 1\% FBS-containing media for $24 \mathrm{~h}$ to arrest them in $\mathrm{G}_{0}$ phase of the cell cycle. Cells $\left(1 \times 10^{5}\right.$ cells $\left./ \mathrm{ml}\right)$ were treated with $\mathrm{IC}_{50}$ and $\mathrm{IC}_{80}$ concentrations of $\mathrm{Feq}_{3}$ for 4, 8 and $24 \mathrm{~h}$, and then the total cells were collected and washed in PBS after gentle centrifugation at $300 \mathrm{~g}$ for $5 \mathrm{~min}$. The cell pellets were fixed by resuspending them in $0.5 \mathrm{ml}$ of $70 \%$ ethanol for $30 \mathrm{~min}$, centrifuging at $300 \mathrm{~g}$ for $10 \mathrm{~min}$, and washing twice with ice-cold PBS to remove residual ethanol. The pellets were resuspended in $0.5 \mathrm{ml}$ of PBS containing PI $(50 \mu \mathrm{g} / \mathrm{ml})$ and RNase $(20 \mu \mathrm{g} / \mathrm{ml})$, and then incubated at $37^{\circ} \mathrm{C}$ for $1 \mathrm{~h}$ and studied using a FACScan flow cytometer (Beckman Coulter, $\mathrm{XL} \cdot \mathrm{MCL}^{\mathrm{TM}}$, USA). A minimum of 10,000 cells were collected and the cell distribution in each phase (sub- $\mathrm{G}_{1}, \mathrm{G}_{0} / \mathrm{G}_{1}, \mathrm{~S}$ and $\mathrm{G}_{2} / \mathrm{M}$ phases) of the cell cycle was determined using WinMDI software.

\section{Cellular ROS and GSH formation assay}

The redox-sensitive fluorescent probe 2',7'-dichlorodihydrofluorescein diacetate (DCFH-DA) was used to assess the intracellular level of ROS [43]. The GSH content was determined, measuring the formation of a fluorescent complex of $o$-phthalaldehyde (OPT) with reduced GSH [44]. To measure ROS and GSH generation, cells $\left(1 \times 10^{5}\right.$ cells $\left./ \mathrm{ml}\right)$ were exposed to $\mathrm{IC}_{50}$ and $\mathrm{IC}_{80}$ concentrations of $\mathrm{Feq}_{3}$ for 4, 8 and $24 \mathrm{~h}$. The negative controls, the DCFH-DA and OPT, were replaced with $1 \times$ PBS under the same conditions. The fluorescence intensity in cells was determined using a FACScan flow cytometer (Beckman Coulter, $\mathrm{XL} \cdot \mathrm{MCL}^{\mathrm{TM}}$, USA) and WinMDI software.

\section{Reverse transcription-polymerase chain reaction (RT-PCR) assay}

RNA preparations were extracted from the cells $\left(1 \times 10^{5}\right.$ cells $\left./ \mathrm{ml}\right)$ that were treated with $\mathrm{IC}_{50}$ concentrations of $\mathrm{Feq}_{3}$ for 4,8 and $16 \mathrm{~h}$ using the Trizol reagent (Invitrogen, Carlsbad, CA, USA). Single stranded cDNA was transcribed by priming with oligo-dT using SAMscript reverse transcriptase (GeneMark, Taipei, Taiwan). PCR amplification of the cDNA was done in a reaction mixture containing Taq polymerase. The primers were as follows: cdc2 (709 bp), 5'-GGTTCC TAGTACTGCAATTCG-3' and 5'-TTTGCCAGAAATCGTTTGG-3'; cyclin B1 (191 bp), 5'- CAGTCAGACCAAAATACCTACTGGGT-3' and 5'-ACACCAACCAGC TGCAGCATCTTCTT-3'; cyclin D (172 bp), 5'-CAAACAGATCATCCGCAAAC-3' and 5'-GCGTGTGAGGCGGTAGT-3'-3'; cdk4 (208 bp), 5'-ACGCCTGTGGTGGTTACG CT-3' and 5'-CCATCTCTGGCACCACTGAC-3'; p53 (293 bp), 5'-CAGCCAAGTCTGTGACTT GCACGTAC -3' and 5'-CTATGTCGAAAAGTGTTTCTGTCATC-3'; p21 (172 bp), 5'-AGATGT CCAGCCAGCTGCACCTGAC-3' and 5'-CTATGTCGAAAGTGTTTCTGTCATC -3'; bax (366 bp), 5' - AAGCTGAGCGAGTGTCTCAAGCGC-3' and 5'-TCCCGCCACAAAGATGGTCACG -3'; bcl-2 (367 bp), 5'-AGATGTCCAGCCAGCTGCACCTGAC-3' and 5'-AGATAGGCACCCAGG GTGATGCAAGCT -3'; cytochrome $c$ (339 bp), 5'-AGACTCACCCGTGCTTCA GT-3' and 5'- ACT CCCAATCAGGCATGAAC-3'; bid (424 bp), 5'-CGAAGACGAGCTGCAGAC-3' and 5'CTCGTTTCTAACCAAGTT CC -3'; caspase-9 (543 bp), 5'- ACCCTGCGGAACCTCAAA GC -3' and 5'GGACACAAAACCTGGAAAAGTTG -3'; caspase-8 (426 bp), 5'-GCCAATCACTTG CTGGAAAACC -3' and 5'-TCTCTGCCTCTGCTCCCATTTAG-3'; TNF- $\alpha$ (224 bp), 5'-TTCCTC ACTCACACCATCAGCC - $3^{\prime}$ and 5'-TGCCCAGATTCAGCAAAGTCC-3'; TNF-R1 (132 bp), 5'- AGTGCTGTTGCCCCTGGTCATTTTCTT-3' and 5'-TTTTCAGGTGTCGATTTCCCA CAAAC 
AAT-3'; TNF-R2 (176 bp), 5'-TGGAAACTCAAGC CTGCACTCGGGAA-3' and 5'- GGGCTTGCACACC ACGTCTGATGTTT-3'; FasL (549 bp), 5'-CAGTGAC TGAC ATCAACTCC -3 ' and 5'- CCTTGGGTTTTCCT TTCTGTGC-3'; Fas (264 bp), 5'-CACCCC CGAAAA TGTTCAATAAT-3' and 5'-GTTCCAGGTATCTGC TTCAGTTT -3'; TRAIL (417 bp), 5'-CAAAGACAGA GTGGCTGACCCC-3' and 5'-ATTCGTTCCAAC AAACCCGAG-3'; TRAIL-R1 (506 bp), 5'-CTGAGCA ACGCAGACTCGCTCTCCAC-3' and 5'-TCCAAG GACACGGCAGAGCCTGTGCCAT-3'; TRAIL-R2 (502 bp), 5'-GCCTCATGGACAATG AGATAAAGGTG GCT-3' and 5'-CCAAATCTCAAAGTACGCACAA ACGG-3'; TRADD (245 bp), 5'-GGTTCCTTCTGCGGC TATTGCTGA-3' and 5'-TGAAACTGTAAGGGC TGGCTGTAA-3'; FADD (180 bp), 5'-CCTGCGGG AGTAGTTGGAAAGTTG-3' and 5'- GCATGGGCTC TGGTGAAGGAT-3'; caspase-3 (498 bp), 5'-AGCAC TGGAATGACA TCTCGGT-3' and 5'-CAGCATGG CACAAAGCGAC-3'; and $\beta$-actin (295 bp), 5'-TCACCCACACTGTGCCCATCTACGA-3' and 5'-CAGCGGAACCGCTCATTGCCAATCG-3'. The amplified RT-PCR products were electrophoresed on a $2 \%$ agarose gel, visualized by ethidium bromide staining and photographed under ultraviolet light. The obtained bands were visualized by image J software and levels were normalized for $\beta$-actin expression.

\section{Caspase inhibitor assay}

Cells were plated in white 96-well plates at $1 \times$ $10^{4}$ cells per well and were allowed to attach. For the caspase inhibitor assay, cells were pre-treated with $10 \mu \mathrm{M}$ caspase-9 inhibitor (Z-LEHD-FMK), caspase-8 inhibitor (Z-IETD-FMK), and caspase-3 inhibitor (Z-DEVD-FMK) for 30 minutes. Then the cells were incubated with the $\mathrm{IC}_{50}$ concentration of $\mathrm{Feq}_{3}$ for $24 \mathrm{~h}$, and the cell viability was measured using the MTT reagent, as described in the cell viability assay section.

\section{Statistical analysis}

The experimental results were presented as mean \pm standard deviation (SD). Statistically significant differences were determined using independent and paired Student's $t$-test on unpaired and paired samples, respectively. A value of $p<0.05$ was regarded as significant in all experiments. Data were analyzed and relevant figures plotted using SigmaPlot Version 8.0 (San Rafacel, CA, USA).

\section{Author contributions}

Leong-Perng Chan performed research, analyzed data, and edited the manuscript. Po-Lin Kuo edited the manuscript and supervised study. Ya-Ping Tseng performed research. Cheng Liu, Hsiou-Yu Ding, ShengMing Pan, Feng-Yu Chiang, Ling-Feng Wang and TzungHan Chou provided technical and material support. ChiaHua Liang designed, interpreted and analyzed data as well as wrote the manuscript.

\section{CONFLICTS OF INTEREST}

All the authors have read and approved the final manuscript, and there is no known conflicts of interest.

\section{GRANT SUPPORT}

The authors would like to thank the Ministry of Science and Technology, Taiwan, Republic of China (MOST 103-2320-B-04-001-MY3 and MOST 105-2622-E-041-002-CC3), the health and welfare surcharge of tobacco products, the Ministry of Health and Welfare, Taiwan, Republic of China (MOHW105TDU-B-212-134007), and the Kaohsiung Medical University Hospital, Taiwan, Republic of China (KMUH102-2M35 and KMUH105-5R38).

\section{REFERENCES}

1. Zscheppang K, Kurth I, Wachtel N, Dubrovska A, KunzSchughart LA, Cordes N. Efficacy of Beta1 Integrin and EGFR Targeting in Sphere-Forming Human Head and Neck Cancer Cells. J Cancer. 2016; 7:736-745.

2. Chan LP, Wang LF, Chiang FY, Lee KW, Kuo PL, Liang CH. IL-8 promotes HNSCC progression on CXCR1/2meidated NOD1/RIP2 signaling pathway. Oncotarget. 2016; 7:61820-31. https://doi.org/10.18632/oncotarget.11445.

3. Morris ZS, Harari PM. Interaction of radiation therapy with molecular targeted agents. J Clin Oncol. 2014; 32:2886-2893.

4. Smith DM, Kazi A, Smith L, Long TE, Heldreth B, Turos E, Dou QP. A novel beta-lactam antibiotic activates tumor cell apoptotic program by inducing DNA damage. Mol Pharmacol. 2002; 61:1348-1358.

5. Chan LP, Chou TH, Ding HY, Chen PR, Chiang FY, Kuo $\mathrm{PL}$, Liang $\mathrm{CH}$. Apigenin induces apoptosis via tumor necrosis factor receptor- and Bcl-2-mediated pathway and enhances susceptibility of head and neck squamous cell carcinoma to 5-fluorouracil and cisplatin. Biochim Biophys Acta. 2012; 1820:1081-1091.

6. Liang $\mathrm{CH}$, Wang $\mathrm{GH}$, Chou TH, Wang SH, Lin RJ, Chan LP, So EC, Sheu JH. 5-epi-Sinuleptolide induces cell cycle arrest and apoptosis through tumor necrosis factor/ mitochondria-mediated caspase signaling pathway in human skin cancer cells. Biochim Biophys Acta. 2012; 1820:1149-1157.

7. Wu CH, Liang CH, Shiu LY, Chang LC, Lin TS, Lan CC, Tsai JC, Wong TW, Wei KJ, Lin TK, Chang NS, Sheu 
HM. Solanum incanum extract (SR-T100) induces human cutaneous squamous cell carcinoma apoptosis through modulating tumor necrosis factor receptor signaling pathway. J Dermatol Sci. 2011; 63:83-92.

8. Kiraz Y, Adan A, Kartal Yandim M, Baran Y. Major apoptotic mechanisms and genes involved in apoptosis. Tumour Biol. 2016; 37:8471-8486.

9. Amarante-Mendes GP, Griffith TS. Therapeutic applications of TRAIL receptor agonists in cancer and beyond. Pharmacol Ther. 2015; 155:117-131.

10. Callari M, Aldrich-Wright JR, De Souza PL, Stenzel MH. Polymers with platinum drugs and other macromolecular metal complexes for cancer treatment. Prog Polym Sci. 2014; 39:1614-1643.

11. Dash SK, Chattopadhyay S, Ghosh T, Tripathy S, Das S, Das D, Roy S. Antileukemic Efficacy of Monomeric Manganese-Based Metal Complex on KG-1A and K562 Cell Lines. ISRN Oncol. 2013; 2013:709269.

12. Rauen U, Petrat F, Sustmann R, de Groot H. Ironinduced mitochondrial permeability transition in cultured hepatocytes. J Hepatol. 2004; 40:607-615.

13. Leanderson $P$, Tagesson C. Iron bound to the lipophilic iron chelator, 8-hydroxyquinoline, causes DNA strand breakage in cultured lung cells. Carcinogenesis. 1996; 17:545-550.

14. Buss JL, Greene BT, Turner J, Torti FM, Torti SV. Iron chelators in cancer chemotherapy. Curr Top Med Chem. 2004; 4:1623-1635.

15. Yin Z, Wang B, Chen G, Zhan M. One-dimensional 8-hydroxyquinoline metal complex nanomaterials: synthesis, optoelectronic properties, and applications. J Mater Sci. 2011; 46:2397-2399.

16. Shridhar AH, Keshavayya J, Hoskeri JH. Synthesis of 1,3,4-oxadiazole incorporated azo dye derivatives as a potent biological activity molecules. Int J Pharm Pharm Sci. 2012; 4:386-390.

17. Eweas AF, Allam G, Abuelsaad AS, ALGhamdi AH, Maghrabi IA. Design, synthesis, anti-schistosomal activity and molecular docking of novel 8-hydroxyquinoline-5sufonyl 1,4-diazepine derivatives. Bioorg Chem. 2013; $46: 17-25$.

18. Liang L, Zhang Z. Gambogic Acid Inhibits Malignant Melanoma Cell Proliferation Through Mitochondrial p66shc/ROS-p53/Bax-Mediated Apoptosis. Cell Physiol Biochem. 2016; 38:1618-1630.

19. Bishayee K, Ghosh S, Mukherjee A, Sadhukhan R, Mondal J, Khuda-Bukhsh AR. Quercetin induces cytochrome-c release and ROS accumulation to promote apoptosis and arrest the cell cycle in $\mathrm{G} 2 / \mathrm{M}$, in cervical carcinoma: signal cascade and drug-DNA interaction. Cell Prolif. 2013; 46:153-163.

20. Guicciardi ME, Gores GJ. Life and death by death receptors. FASEB J. 2009; 23:1625-1637.

21. Ding WQ, Liu B, Vaught JL, Palmiter RD, Lind SE. Clioquinol and docosahexaenoic acid act synergistically to kill tumor cells. Mol Cancer Ther. 2006; 5:1864-1872.

22. Cassat JE, Skaar EP. Iron in infection and immunity. Cell Host Microbe. 2013; 13:509-519.

23. Leanderson P, Tagesson C. Iron bound to the lipophilic iron chelator, 8-hydroxyquinoline, causes DNA strand breakage in cultured lung cells. Carcinogenesis. 1996; 17:545-50.

24. Su R, Xue WD, Feng Y, Wang JH, Yi D. Sensitization mechanism of tris(8-hydroxyquinoline)iron (III) on TiO2 anatase (101) surface. Wuli Huaxue Xuebao. 2009; 25:947-952.

25. Zhu W, Xie W, Pan T, Xu P, Fridkin M, Zheng H, Jankovic J, Youdim MB, Le W. Prevention and restoration of lactacystin-induced nigrostriatal dopamine neuron degeneration by novel brain-permeable iron chelators. FASEB J. 2007; 21:3835-3844.

26. Elmore S. Apoptosis: a review of programmed cell death. Toxicol Pathol. 2007; 35:495-516.

27. Süsse S, Scholz CJ, Bürkle A, Wiesmüller L. Poly(ADPribose) polymerase (PARP-1) and p53 independently function in regulating double-strand break repair in primate cells. Nucleic Acids Res. 2004; 32:669-680.

28. Krysko DV, Vanden Berghe T, D'Herde K, Vandenabeele P. Apoptosis and necrosis: detection, discrimination and phagocytosis. Methods. 2008; 44:205-221.

29. Duronio RJ, Xiong Y. Signaling pathways that control cell proliferation. Cold Spring Harb Perspect Biol. 2013; 5:a008904.

30. Barrera G. Oxidative stress and lipid peroxidation products in cancer progression and therapy. ISRN Oncol. 2012; 2012:137289.

31. Di Meo S, Reed TT, Venditti P, Victor VM. Role of ROS and RNS Sources in Physiological and Pathological Conditions. Oxid Med Cell Longev. 2016; 2016:1245049.

32. Lu GD, Shen HM, Chung MC, Ong CN. Critical role of oxidative stress and sustained JNK activation in aloeemodin-mediated apoptotic cell death in human hepatoma cells. Carcinogenesis. 2007; 28:1937-1945.

33. Abbas T, Dutta A. p21 in cancer: intricate networks and multiple activities. Nat Rev Cancer. 2009; 9:400-414.

34. Martinou JC, Youle RJ. Mitochondria in apoptosis: Bcl-2 family members and mitochondrial dynamics. Dev Cell. 2011; 21:92-101.

35. Gómez-Crisóstomo NP, López-Marure R, Zapata E, Zazueta C, Martínez-Abundis E. Bax induces cytochrome c release by multiple mechanisms in mitochondria from MCF7 cells. J Bioenerg Biomembr. 2013; 45:441-448.

36. Srivastava RK. TRAIL/Apo-2L: mechanisms and clinical applications in cancer. Neoplasia. 2001; 3:535-546.

37. Barilli A, Atzeri C, Bassanetti I, Ingoglia F, Dall'Asta V, Bussolati O, Maffini M, Mucchino C, Marchiò L. Oxidative stress induced by copper and iron complexes with 8-hydroxyquinoline derivatives causes paraptotic death of HeLa cancer cells. Mol Pharm. 2014; 11:1151-63. 
38. Jungwirth U, Gojo J, Tuder T, Walko G, Holcmann M, Schöfl T, Nowikovsky K, Wilfinger N, Schoonhoven S, Kowol CR, Lemmens-Gruber R, Heffeter P, Keppler BK, Berger W. Calpain-mediated integrin deregulation as a novel mode of action for the anticancer gallium compound KP46. Mol Cancer Ther. 2014; 13:2436-2449.

39. Wilfinger N, Austin S, Scheiber-Mojdehkar B, Berger W, Reipert S, Praschberger M, Paur J, Trondl R, Keppler BK, Zielinski CC, Nowikovsky K. Novel p53-dependent anticancer strategy by targeting iron signaling and BNIP3Linduced mitophagy. Oncotarget. 2016; 7:1242-61. https:// doi.org/10.18632/oncotarget.6233.

40. Bouchier-Hayes L, McBride S, van Geelen CM, Nance $\mathrm{S}$, Lewis LK, Pinkoski MJ, Beere HM. Fas ligand gene expression is directly regulated by stress-inducible heat shock transcription factor-1. Cell Death Differ. 2010; 17:1034-1046.
41. Waring P, Müllbacher A. Cell death induced by the Fas/ Fas ligand pathway and its role in pathology. Immunol Cell Biol. 1999; 77:312-317.

42. Micheau O, Solary E, Hammann A, Dimanche-Boitrel MT. Fas ligand-independent, FADD-mediated activation of the Fas death pathway by anticancer drugs. J Biol Chem. 1999; 274:7987-7992.

43. Dikalov SI, Harrison DG. Methods for detection of mitochondrial and cellular reactive oxygen species. Antioxid Redox Signal. 2014; 20:372-382.

44. Stevenson D, Wokosin D, Girkin J, Grant MH. Measurement of the intracellular distribution of reduced glutathione in cultured rat hepatocytes using monochlorobimane and confocal laser scanning microscopy. Toxicol In Vitro. 2002; 16:609-619. 